\title{
Repeated electoral competition over non-linear income tax schedules ${ }^{1}$
}

\author{
Georges Casamatta ${ }^{2}$ \\ Toulouse School of Economics \\ (GREMAQ-CNRS and CEPR)
}

Helmuth Cremer

Toulouse School of Economics

(GREMAQ, IDEI and Institut universitaire de France)

Philippe De Donder

Toulouse School of Economics

(GREMAQ-CNRS and IDEI)

This version: April 2010

\footnotetext{
${ }^{1}$ Financial support from Agence Nationale de la Recherche (France) within the framework of the ANR "Retraite" (ANR-05-BLAN-0020) is gratefully acknowledged. We thank Arnaud Dellis, John Duggan, Jean Hindriks, Thomas Mariotti, Jérôme Renault, John Roemer and Karine van der Straeten for their comments as well as participants to the Vèmes Journées Louis-André Gérard Varet (Marseille, June 2006), the 2006 Social Choice and Welfare conference (Istanbul), the 2007 ESEM conference (Budapest), the 2007 ASSET conference (Padova) and to a seminar at Universita Cattolica del Sacro Cuore (Milan). The paper has been revised while the last author was visiting Yale University. He thanks Yale Economics Department for its hospitality.

${ }^{2}$ Corresponding author. Email: georges.casamatta@univ-tlse1.fr
} 


\begin{abstract}
We consider a repeated electoral competition game between two parties, each representing a constituent with a given income level. Parties are unable to commit to a policy before the election; they choose a non-linear income tax schedule once elected. In each period, citizens cast a vote either for the incumbent or for the challenger. We first show that there exist (pure strategy) subgame perfect equilibria where both parties choose the most-preferred tax schedule of their constituent, subject to the constraint that they are reelected. We characterize a specific class of these $B P R$ (Best Policy with Reelection) equilibria in which one of the parties plays its constituent's unconstrained optimal tax function. Equilibrium tax schedules are always piecewise linear. Depending on the income levels of the two parties' constituents, we obtain either classical left-vsright equilibria (where the poor vote for one party and the rich for the other one) or ends-against-the-middle equilibria (where both poor and rich vote for one party while the middle class votes for the other party). In both types of equilibria both parties propose the same tax schedule to a subset of the population.
\end{abstract}

Keywords: Postelection politics, no commitment, ends-against-the-middle, piecewise linear income tax

JEL codes: D72, H24 


\section{Introduction}

The determination of income taxes through a democratic process has been extensively studied over the last three decades. In their seminal contributions Romer (1975) and Roberts (1977) studied the determination of a linear income tax schedule under majority voting. This problem being unidimensional, a Condorcet winner (majority voting equilibrium) exists under quite weak assumptions. It is given by the most-preferred tax of the individuals with median productivity. This implies that the electoral competition game between two parties who are able to commit at the campaign stage has a unique equilibrium in pure strategies, which is given by the Condorcet winner.

The restriction to a linear tax scheme is artificial. It is made for simplicity but cannot be justified by informational or practical considerations. In reality income tax schedules are typically non-linear (most often piecewise linear), and marginal tax rates vary with income. A satisfactory treatment of the democratic choice of income taxes should thus allow for non-linear taxes. However, with a non-linear tax, the policy space becomes multi-dimensional, leading to voting cycles and the non-existence of a pure strategy Nash equilibrium of the electoral competition game (Plott (1967)).

Confronted with this difficulty, two different approaches have been adopted. The first well treaded approach consists in keeping the framework of the Downsian electoral competition but to study solution concepts different from the pure-strategy Nash equilibrium. Recall that key features of Downsian models is that they concentrate on one-shot games and that parties are able to commit to their announced policy. The alternative solution concepts that have been considered include the uncovered set, obtained by eliminating weakly dominated strategies (De Donder and Hindriks (2003)) or the bipartisan set, which is the support of mixed strategies played in equilibrium (De Donder and Hindriks (2003), Carbonell-Nicolau and Ok (2007)). Roemer (2001) does depart from the strict Downsian framework but keeps the assumption that parties can commit to any policy at the electoral stage. This area of research has been dubbed "preelection politics" by Persson and Tabellini (2000).

The second direction of research, referred to as "postelection politics", assumes that 
electoral promises are not binding or too vague to matter. Consequently, parties are effectively unable to commit to any policy before the election. Few papers have followed this approach when modelling political competition over tax functions. Moreover, these contributions have focused on one-shot games in which candidates (who have preferences over the different policies) implement, if elected, their own most-preferred policy. The policy space is thus reduced to the set of individually optimal policies so that we essentially return to a single dimensional problem. Roëll (1996) and Bohn and Stuart (2005) show that a Condorcet winning non-linear taxation schedule exists under rather mild conditions.

We follow this second strand of research and we take the analysis a step forward by considering an infinitely repeated electoral competition game with no policy commitment, building on the work by Duggan (2000) and Banks and Duggan (2008). In our model, two parties with known preferences compete repeatedly. There is an election in each period and the party receiving the most votes is elected for that period (majority rule). Parties are not able to commit to the policy they would implement if elected. The elected party chooses a tax schedule for the current period and this process is repeated indefinitely. Citizens then cast their votes on the basis of their expectations of parties' choices.

We show that, when the parties are sufficiently patient, there exist (pure strategy) subgame perfect equilibria in which the incumbent party in any given period adopts the policy that maximizes the utility of its constituent under the constraint that it is reelected (i.e., that it receives at least $50 \%$ of the votes). We label these BPR (Best Policy with Reelection) equilibria.

We apply this equilibrium concept to a model where citizens differ only according to their exogenous income level. The income distribution is positively skewed, with the median income below the mean. The set of admissible tax schedules consists of all functions that (i) are continuous, (ii) entail marginal tax rates that are nonnegative and do not exceed one ${ }^{1}$ and (iii) satisfy the government budget constraint. The identity of the parties' constituents are exogenously given. One of the parties, $A$, represents a

\footnotetext{
${ }^{1}$ Where derivatives exist; we do not impose differentiability.
} 
constituent with income below the median level, while party $B$ stands for a constituent with income above the median level.

We focus on $B P R$ equilibria in which one of the two parties proposes the mostpreferred tax schedule of the constituent it represents (absent any reelection consideration). We distinguish between four types of equilibria and show that the specific type that emerges depends on the income levels of the constituents of the two parties. The party whose constituent is more moderate offers the most-preferred tax schedule of its constituent, while the other party proposes a policy that satisfies its constituent and voters up to the median income voter, or an "ends-against-the-middle" policy (where both poor and rich people vote for one party while the middle class vote for the other party) if its constituent is very extreme (very far from the median income level).

All $B P R$ equilibria, whatever the identity of the two constituents, exhibit piecewise linear tax functions proposed by both parties. Furthermore, in all equilibria, both parties propose the same tax policy to a subset of the electorate. We discuss these features of $B P R$ equilibria in the concluding section.

\section{The model}

\subsection{The economic model}

The economic modelling is borrowed from Roemer (2006). There is a continuum of citizens/voters identified by their exogenous income $y$, which is distributed on the support $\left[y_{-}, y_{+}\right]$according to a probability measure $H$, whose distribution function is denoted $F$. We denote by $f$ the density function. We assume that the distribution function is positively skewed, with the median income $y_{m}$ strictly lower than the average income $\bar{y}$.

Let $T(y)$ denote a generic tax function. We restrict the set of admissible tax func- 
tions, denoted by $\Omega$, to functions that are (i) continuous, (ii) satisfy ${ }^{2}$

$$
0 \leq T^{\prime}(y) \leq 1
$$

where differentiable, and (iii) are purely redistributive (there is no revenue requirement) so that ${ }^{3}$

$$
\int_{y_{-}}^{y_{+}} T(y) f(y) d y=0 .
$$

We do not explicitly impose the limited liability condition $T(y) \leq y$ since this constraint is not binding at any of the equilibria we consider. Consumption of an individual with pre-tax income $y$ is denoted by $c(y)=y-T(y) .{ }^{4}$ Utility is increasing in consumption and denoted by the function $u(c)$ with $u^{\prime}>0$ and $u^{\prime \prime} \leq 0$. Let $v(y, T)=u(y-T)$ denote the utility level of an individual with pre-tax income $y$ who pays a tax of $T$.

\subsection{The political competition game}

There are two political parties denoted by $A$ and $B$. Following Duggan (2000) or Banks and Duggan (2008), we study a repeated elections model with infinite horizon. ${ }^{5}$ The players in this game are the two parties and the voters. At the beginning of each period $t$, an election takes place in which voters decide whether to reelect the incumbent party or to appoint the challenger. The party obtaining the most votes is elected (majority rule), and gets to choose a tax schedule $T_{t}$ for the current period. When the two parties

\footnotetext{
${ }^{2}$ This condition implies that both tax liabilities and after-tax income are non-decreasing functions of pre-tax income. Such a condition is usually derived instead of assumed in the optimal tax literature with endogenous income. Alternatively, we could replace the upperbound on the marginal tax rate by $\alpha<1$ as in Roemer (2009). One interpretation of $\alpha$ is that both parties agree not to enact policies with too large marginal tax rates (to avoid the distortionary impact of unmodelled labor-leisure substitution). With this interpretation, marginal tax rates below $\alpha$ create few if any labor supply distortions. Introducing such an $\alpha$ would not change substantially our results.

${ }^{3}$ Adding an exogenous revenue requirement would not change our results.

${ }^{4}$ Given the one-to-one relationship between tax functions $T$ and after-tax consumption functions $c$, the game we describe is equivalent to one where parties announce consumption functions rather than tax functions. In the rest of the paper, we sometimes adopt the shortcut "a party proposes a consumption function" rather than writing that "a party proposes a tax function that results in the following consumption function".

${ }^{5}$ The main difference between our setting and these models is that we assume that the preferences of the parties are observable to the voters. In Duggan (2000) and Banks and Duggan (2008), the voters cannot observe the type of the challenger, which is randomly drawn.
} 
receive the same proportion of votes, the incumbent party is reelected for sure. ${ }^{6}$ The same sequence of events is repeated indefinitely.

An important feature of this model is that elections are not preceded by a campaign stage with policy announcements. Before the election, parties are not able to commit to the policy they would implement if elected. This assumption is in contrast with most election models in the literature and it is crucial to our results. Consider a static game with policy commitment. In the absence of a Condorcet winner (as is the case in our model), for any given policy proposed by a party, the other party can put forward an alternative policy preferred by a majority of voters and thus win the election. This explains why a (pure strategy) Nash equilibrium fails to exist in this static game. ${ }^{7}$ This result hinges on the commitment assumption: the winning party implements, once elected, the policy announced during the campaign. This is a strong assumption: when there is no commitment and parties have policy preferences, the elected party should implement its ideal policy in a one shot game. The only credible promises at the campaign stage thus correspond to the ideal policies of the two parties! When elections are repeated, the set of credible promises is enlarged as the party in power in a given period balances the short-term benefit of implementing a favored policy with the longterm benefit of being reelected in future periods. This is precisely the trade-off that we seek to capture with our modeling. ${ }^{8}$

We now describe the payoffs and strategies of the two types of actors (namely parties and voters), starting with the two parties. Party $i(i=A, B)$ represents constituents with income $y_{i}$, with $y_{A}<y_{m}<y_{B}$. Its payoff from the sequence $\left\{T_{t}().\right\}$ of outcomes is given by

$$
(1-\delta) \sum_{t=1}^{\infty} \delta^{t-1}\left[v\left(y_{i}, T_{t}\left(y_{i}\right)\right)+\beta \omega_{i t}\right] .
$$

The parties' payoffs come from two sources. First, parties care about the tax function enacted because it determines the utility of their constituents. Parties also care about

\footnotetext{
${ }^{6}$ This assumption is not crucial to our results. We show later on in the paper that our results extend to the case in which the incumbent is reelected with a positive probability strictly lower than one in the case of a tie. We however stick to this assumption for expositional clarity.

${ }^{7}$ This is true whether parties have policy preferences or not. See Duggan and Fey (2005).

${ }^{8}$ For the sake of simplicity, we do not model the campaign announcement stage. It is plain however that parties could not credibly announce policies that are not equilibrium outcomes.
} 
winning the elections per se, enjoying an additional payoff $\beta>0$ (spoils of office, ego rents, etc.) when they win the elections at time $t$. Accordingly, $\omega_{i t}$ denotes the indicator function taking the value 1 if party $i$ is elected in period $t$ (and 0 otherwise). The discount factor is denoted by $0<\delta<1$. A (pure) strategy of party $i$ specifies the policy $T_{t}($.$) chosen once elected in period t$, for every possible history of the game at date $t$.

A type $y$ voter's payoff from the sequence $\left\{T_{t}().\right\}$ of policy outcomes is the discounted sum of per-period utility levels:

$$
(1-\delta) \sum_{t=1}^{\infty} \delta^{t-1} v\left(y, T_{t}(y)\right),
$$

where $\delta$ is the same time discount factor as for parties. ${ }^{9}$

A (pure) strategy of voter $j$ specifies, for every possible history of the game, whether he votes for the incumbent or for the challenger. We assume that voters act as though pivotal in the election. ${ }^{10}$ They vote for the incumbent if the continuation value from reelecting him is greater than the one obtained when electing the challenger. When indifferent, they are assumed to vote for the incumbent. ${ }^{11}$ This approach is called prospective voting.

We are now in a position to characterize a special class of equilibria of this game.

\subsection{Best Policy with Reelection equilibria}

We first define the optimal tax schedules of a given party $i$. We distinguish between the unconstrained optimum and the constrained optimum. Let $T_{i}^{o p t}($.$) denote the uncon-$ strained optimal tax schedule of party $i$ absent electoral considerations. It is obtained by maximizing the utility of the party's constituent (with income $y_{i}$ ) over the entire set

\footnotetext{
${ }^{9}$ The assumption of identical discount factors is made purely for convenience. Considering different discount factors for the parties and the citizens would not affect the results.

${ }^{10}$ This condition can be seen as the analogous of the elimination of weakly dominated strategies, a criterion widely used in static games to get rid of "unreasonable" equilibria. This also corresponds to stage-undominated strategies in dynamic models with a finite number of voters (see Baron and Kalai (1993)).

${ }^{11}$ This assumption is needed to solve the optimization program of the parties. It can be justified by considering that voters behave according to the old axiom "better the devil you know than the devil you don't" when both the incumbent and the challenger propose the same after-tax income to them.
} 
of admissible strategies:

$$
T_{i}^{o p t}(.)=\arg \max _{T \in \Omega} v\left(y_{i}, T\left(y_{i}\right)\right), i=A, B
$$

The constrained optimum $T_{i}^{B P R}\left(., T_{j}\right)$, on the other hand, is the tax function that maximizes party $i$ 's constituent's utility under the constraint that at least $50 \%$ of the voters prefer this tax function to $T_{j}$ :

$$
\begin{aligned}
& T_{i}^{B P R}\left(., T_{j}\right)= \arg \max _{T \in \Omega} v\left(y_{i}, T\left(y_{i}\right)\right), \quad i, j=A, B, \quad i \neq j \\
& \text { s. t. } \quad H\left(y: v(y, T(y)) \geq v\left(y, T_{j}(y)\right)\right) \geq 1 / 2 .
\end{aligned}
$$

The following Proposition states that, when the discount factor is sufficiently large, there exists a (pure strategy) subgame perfect equilibrium of the electoral competition game, where both parties offer their preferred policy under the constraint of reelection.

Proposition 1 Assume that there exist two tax schedules $T_{A}^{*}($.$) and T_{B}^{*}($.$) such that$ $T_{A}^{*}()=.T_{A}^{B P R}\left(., T_{B}^{*}\right)$ and $T_{B}^{*}()=.T_{B}^{B P R}\left(., T_{A}^{*}\right)$. Then there exists a subgame perfect equilibrium, called BPR equilibrium, with the parties playing $T_{i}^{*}($.$) when in office if both$ parties are patient enough (i.e., if $\delta$ is large enough).

To prove Proposition 1, we resort to the concepts of initial path, punishments and simple strategy profiles introduced by Abreu (1988). Those concepts are formally defined in the proof of Proposition 1 in Appendix A. A strategy profile for the parties is a rule prescribing an initial path and punishments for any deviation from the initial path, or from a previously prescribed punishment, where a path (or punishment) is an infinite stream of one-period action profiles. In the $B P R$ equilibrium we study, the initial path (denoted by $Q^{0}$ ) prescribes that each party $i$, once elected, proposes its optimal constrained policy, $T_{i}^{*}($.$) . If any party deviates from this prescription, it is to$ be punished in all subsequent periods. We restrict ourselves to simple strategy profiles, where punishments are history-independent, in the sense that we specify the same punishment $Q^{i}$ for any deviation, after any previous history, by party $i$. The punishments used to sustain the BPR equilibrium are as follows: if party $i$ is in power and deviates in period $t$, then the other party $j(j \neq i)$ plays its optimal constrained policy $T_{j}^{*}($.$) if$ 
elected in $t+1$, while party $i$ would play if elected a policy that a majority of voters dislike compared to $T_{j}^{*}($.$) . The exact same punishment is repeated for all periods after$ $t+1$.

These simple strategies define the following play of the game. As long as both parties have played according to $Q^{0}$ in the past (i.e., every incumbent $i$ has always played $\left.T_{i}^{*}().\right)$, the incumbent in the next period also abides by $Q^{0}$ and plays its optimal constrained policy. As soon as one incumbent $i$ deviates from $Q^{0}$ in period $t$, it is punished by both parties switching to the punishment $Q^{i}$ in all subsequent periods. Likewise, if one incumbent $j$ at time $k$ deviates from the required punishment $Q^{i}(i=j$ or $i \neq j)$, it is punished by a move from $Q^{i}$ to $Q^{j}$ in all subsequent periods: parties also get punished if they fail to punish the other party.

We first have to state how voters compute the continuation value associated with both parties at time $t$. This requires that voters anticipate, for any given history of the game, which policy each party would implement if elected at any future period. As usual in the literature, we assume that the expectations of the voters are in line with the strategies used by the parties. That is, if the history of the game is consistent with both parties having played $Q^{0}$ in the past (i.e., incumbents have always implemented their optimal constrained policy), voters assume that they will do so in the future as well. If one incumbent $i$ has just deviated from $Q^{0}$, voters assume that parties will play according to the punishment $Q^{i}$ in the future, and similarly if the incumbent $i$ has just deviated from the prescribed punishment $Q^{j}(j=i$ or $j \neq i)$.

We are now in a position to give the intuition for Proposition 1. Abiding by the initial path $Q^{0}$ at all stages allows the incumbent party $i$ to be reelected (because voters anticipate that parties will play their optimal unconstrained strategies at any stage in the future) and gives this party (who remains in power for ever) a constant stream of pay-offs with two components: the utility from implementing its optimal constrained policy $T_{i}^{*}($.$) and the spoils of office term \beta$. We now test deviations, using Proposition 1 in Abreu (1988) which states that perfection of the candidate equilibrium may be verified by checking "one-shot" deviations alone (i.e., deviations followed by conformity with the strategy profile in question). Observe first that voters gain nothing by deviating 
from their strategy (voting for the party offering them the highest continuation value, computed as explained above) since, with a continuum of voters, no one is decisive. Observe then that, among parties, only the incumbent can deviate at time $t$. If the incumbent deviates from the prescribed $Q^{0}$ at time $t$, voters anticipate that $Q^{i}$ will be played in the future, so that the current incumbent will never be reelected (and thus will lose the spoils of office terms) and will have to do with the optimal constrained policy of the other party. Faced with this prospect, the best deviation by an incumbent at time $t$ consists in playing its optimal unconstrained strategy, to maximize its payoff at time $t$, followed by a stream a lower pay-offs in the future. We show in the Appendix that, unsurprisingly, if the incumbent is patient enough it will prefer to stick with the flow of pay-offs associated with the initial path $Q^{0}$ rather than deviating from this path.

We also have to show that parties have no incentive to deviate from the punishments prescribed. Assume that the history of the game is such that penalty $Q^{i}$ should be played in the next period (i.e., the current incumbent $i$ at time $t-1$ has deviated from its prescribed behavior). A majority of citizens then vote for party $j \neq i$ at time $t$. The punishment $Q^{i}$ is such that party $j$ should play its optimal constrained policy and remain in power in all future periods. This corresponds to the flow of payoffs that this party would obtain with the initial path $Q^{0}$ in case of incumbency, and the same lower bound on this party's patience which guarantees that this party does not deviate from $Q^{0}$ then also ensures that it does not deviate from the punishment $Q^{i}$. As for party $i$, it is voted out of office in period $t$ and remains in the opposition for ever, which robs this party from any decision in the future. ${ }^{12}$ We then obtain that there exists a $B P R$ (subgame perfect) equilibrium as described in Proposition 1 provided that parties are patient enough.

We have assumed so far that, when the two parties receive the same number of votes, the incumbent is reelected for sure. We now argue that Proposition 1 generalizes to the case where the incumbent is reelected with some positive probability (lower than one)

\footnotetext{
${ }^{12}$ If we further assume that party $i$ plays $T_{i}^{o p t}$ in punishment $Q^{i}$ (a policy that a majority of voters dislike compared to $T_{j}^{*}$ ), we further obtain that this party would have no incentive to deviate from its prescribed action under $Q^{i}$, even in the out-of-equilibrium situation where party $i$ would unexpectedly come back to power under punishment $Q^{i}$.
} 
when it obtains the same fraction of votes as the challenger. The payoff when following strategy $Q^{0}$ then becomes a lottery. Assuming without loss of generality that party $A$ is the incumbent, abiding by strategy $Q^{0}$ ensures a flow of lotteries consisting of a payoff of $v\left(y_{A}, T_{A}^{*}\left(y_{A}\right)\right)+\beta$ with some positive probability and a payoff of $v\left(y_{A}, T_{B}^{*}\left(y_{A}\right)\right)$ otherwise. The payoff in case of deviation by $A$ from $Q^{0}$ is not affected and remains given by (14) in the Appendix. It is straightforward to check that, if party $A$ is patient enough, the payoff associated with playing $Q^{0}$ is larger than the payoff obtained if deviating. ${ }^{13}$ Observe that this result is robust to many different ways of specifying the probability that the incumbent is reelected when both parties tie for winning (this probability may be time dependent and may depend or not on the identity of the incumbent at time $t$ ).

In the remainder of the paper, we characterize a specific and particularly interesting class of $B P R$ equilibria, namely those in which one of the parties is not effectively constrained by electoral considerations. In other words, this party offers its constituents' unconstrained optimal policy. We distinguish between four types of equilibria which we first characterize (Sections 4 and 5) before establishing their existence (Section 6).

\section{Individually optimal tax schedules}

Before studying equilibria of the electoral competition game, we describe the optimal tax schedules of individual voters. Ideally, individuals with income $y_{i}$ would like to completely expropriate people with income below and above $y_{i}$, setting their net income to 0 . However, they face the constraints that the tax function must be continuous and that marginal tax rates (where they exist) have to be between 0 and 1 . Under these restrictions, it is plain that they should set a marginal tax rate of 0 to all individuals with income below $y_{i}$ and of 1 to individuals with higher incomes. The optimal tax schedule of an individual with income $y_{i}$ is thus given by ${ }^{14}$

$$
T_{i}^{o p t}(y)=\max \left[y-y_{i}, 0\right]-I_{i}^{o p t},\left(y, y_{i}\right) \in\left[y_{-}, y_{+}\right]^{2}
$$

\footnotetext{
${ }^{13}$ The payoff associated with the lottery is lower than the payoff obtained when the incumbent is reelected with certainty, so that the lower-bound on $\delta$ above which Proposition 1 holds is larger (while remaining strictly less than one).

${ }^{14} \mathrm{~A}$ formal proof, following the same technique as in the proof of Proposition 2, is left to the reader.
} 
where $I_{i}^{\text {opt }}>0$ is the transfer (negative income tax) received by the individual with the lowest income, $y_{-}$. Put differently it is the difference between this individual's after-tax (net) and before-tax (gross) income. Graphically, $I_{i}^{\text {opt }}$ measures the intercept of the net income schedule in the (gross, net) income space $\left[y_{-}, y_{+}\right] \times\left[y_{-}, y_{+}\right]$. It is obtained from the government budget constraint (hereafter GBC) which, using (2) and (5) can be written as

$$
\int_{y_{-}}^{y_{i}}\left(y+I_{i}^{o p t}\right) f(y) d y+\int_{y_{i}}^{y_{+}}\left(y_{i}+I_{i}^{o p t}\right) f(y) d y=\int_{y_{-}}^{y_{+}} y f(y) d y \equiv \bar{y} .
$$

Solving this expression yields

$$
I_{i}^{o p t}=\int_{y_{i}}^{y_{+}}\left(y-y_{i}\right) f(y) d y .
$$

Consequently, the difference between net and gross income of the poorest individual with party $i$ 's $(i=A, B)$ unconstrained optimal tax schedule is given by

$$
\begin{aligned}
I_{A}^{o p t} & =\int_{y_{A}}^{y_{+}}\left(y-y_{A}\right) d F, \\
I_{B}^{o p t} & =\int_{y_{B}}^{y_{+}}\left(y-y_{B}\right) d F,
\end{aligned}
$$

so that $I_{A}^{o p t}>I_{B}^{o p t}>0$ since $y_{A}<y_{B}<y_{+}$.

For some of our arguments it is convenient to define $c_{i}^{\text {opt }}($.$) , the optimal consumption$ function of individuals with income $y_{i}$ :

$$
c_{i}^{o p t}(y)=I_{i}^{o p t}+\min \left[y, y_{i}\right],\left(y, y_{i}\right) \in\left[y_{-}, y_{+}\right]^{2} .
$$

It is optimal in the sense that it is induced by the individual's optimal tax schedule. The unconstrained optimal consumption schedules of parties $A$ and $B$ are represented on Figure 1.

The remainder of the paper concentrates on situations where one party proposes its unconstrained most-preferred policy. To be more precise, we consider BPR equilibria which are such that the reelection constraint is not effectively binding for one of the parties, in the sense that this party $i$ is reelected for sure when playing $T_{i}^{o p t}$. These equilibria have a number of interesting features. We characterize them and show that they exist which in itself is a very interesting (and rather surprising) property. 
In section 4 , party $B$ (representing the richer constituent) offers its unconstrained most-preferred policy, $T_{B}^{o p t}$. We first identify the optimal policy by party $A$ in the set of feasible tax schedules that all below-median income voters prefer to party $B$ 's policy. We then study the optimal policy for party $A$ under the constraint that a non-null set of voters whose income is less than the mean do not favor $A$ 's policy over $B$ 's. We call this policy the best alternative to the simple policy referred to above. Section 5 performs the same exercise when party $A$ proposes its unconstrained most-preferred policy. Section 6 studies the conditions (on the identity of the parties' constituents income levels $y_{A}$ and $\left.y_{B}\right)$ under which these pairs of policies constitute a $B P R$ equilibrium of the electoral game.

Observe that the Best Policy with Reelection $T_{i}^{B P R}\left(., T_{j}\right)$ and the unconstrained optimal policy $T_{i}^{o p t}($.$) do not depend on the shape of the utility functions v$ and $u$. The analysis contained in the rest of the paper is thus valid for any increasing utility function that satisfies condition (17) in Appendix A.

\section{Party B proposes its unconstrained most-preferred pol- icy}

Assume for the time being that $B$ plays its unconstrained optimal strategy $T_{B}^{o p t}$ (or equivalently the consumption function $c_{B}^{\text {opt }}$ ). With this hypothesis, party $B$ 's behavior is well-defined and to characterize the equilibrium we only have to determine party $A$ 's strategy. In other words, we have to determine party $A$ 's $B P R$ reply to $c_{B}^{\text {opt }}$. In this section, we assume that the reelection constraint is binding for party $A$-i.e., that party $A$ would gather strictly less than one half of the vote it were to propose its unconstrained optimal policy $T_{A}^{o p t}$ (or equivalently $c_{A}^{\text {opt }}$ ). Observe from Figure 1 that a necessary and sufficient condition for the reelection constraint to be binding for party A's $B P R$ when faced with $c_{B}^{\text {opt }}$ is that $c_{A}^{\text {opt }}$ intersects $c_{B}^{\text {opt }}$ to the left of $y_{m}$. We then assume throughout this section that the following assumption holds:

Assumption 1: $c_{A}^{\text {opt }}\left(y_{m}\right)<c_{B}^{\text {opt }}\left(y_{m}\right)$.

Under Assumption 1, party $B$ is reelected for sure if it proposes $c_{B}^{\text {opt }}$ while party $A$ enacts its $B P R$ once in office. Party $B$ then has no incentive to choose a schedule 
different from $c_{B}^{o p t}$. This section then concentrates on party A's BPR under Assumption 1. Interestingly it will turn out that this strategy can obey two quite distinct patterns. Under pattern $I$, voters will be divided simply along the income line, with the "poor" supporting party $A$ while the "rich" vote for $B$. The other pattern, $I I$, is of the "endagainst-the-middle" type with the poor and the rich supporting party $A$ while the middle class supports $B$.

Turning to the formal construction of the equilibria, let $c_{i}^{j}\left(x, y_{B}, y_{A}\right)$ denote the consumption level of an individual with income $x$, induced by the tax schedule played in a type $j$ equilibrium by party $i$, when party $B$ represents an individual with income $y_{B}$ and party $A$ an individual with income $y_{A}$. When no ambiguity can arise, we simply use the notation $c_{i}^{j}\left(\right.$.) (and $T_{i}^{j}$ (.) for the corresponding tax function).

We now identify a simple tax function that allows party $A$ to be reelected with the support of all individuals with an income below the median $y_{m}$. Party $A$ 's corresponding after-tax schedule, denoted by $c_{A}^{I B}$, is defined as follows (see Figure 2):

$$
c_{A}^{I B}(y)=\left\{\begin{array}{l}
c_{B}^{o p t}(y)+I_{2}^{I B} \text { if } y-\leq y \leq y_{A} \\
c_{A}^{I B}\left(y_{A}\right) \text { if } y_{A}<y \leq y_{A}^{\prime} \\
c_{B}^{o p t}(y) \text { if } y_{A}^{\prime} \leq y \leq y_{m} \\
c_{B}^{o p t}\left(y_{m}\right) \text { if } y_{m} \leq y \leq y_{+}
\end{array}\right.
$$

All individuals with an income lower than $y_{A}$ face a zero marginal tax rate. As can be seen from Figure 2, we denote by $y_{A}^{\prime}$ the pre-tax income threshold such that (i) individuals with $y_{A} \leq y<y_{A}^{\prime}$ face a marginal tax of one while individuals with $y_{A}^{\prime}<y<y_{m}$ face a zero marginal tax rate, and $(i i) c_{A}^{I B}(y)=c_{B}^{\text {opt }}(y)$ for the individuals whose income $y$ is between $y_{A}^{\prime}$ and $y_{m}$. Above $y_{m}$, marginal tax rates under party $A$ 's policy are all equal to one. It is easy to see that $c_{A}^{I B}($.$) is fully determined by the value$ of $c_{A}^{I B}(0)$-i.e., by $I_{2}^{I B}$ - and we set the value of $I_{2}^{I B}$ such that $c_{A}^{I B}($.$) integrates to the$ mean of the income distribution. ${ }^{15}$

We prove the following Proposition in Appendix B: ${ }^{16}$

\footnotetext{
${ }^{15}$ The formal proof can be found in the working paper version of this article, which is available at http://www.cepr.org/pubs/dps/DP7054.asp.

${ }^{16}$ The proof follows closely the proof of Theorem 4 in Roemer (2009). We are indebted to John Roemer for pointing out this powerful proof method to our attention.
} 
Proposition 2 The function $c_{A}^{I B}(y)$ is the solution to the following optimization program:

$$
\begin{aligned}
& \max c\left(y_{A}\right) \text { such that } \\
& c(y) \geq c_{B}^{\text {opt }}(y) \text { for } y \leq y_{m}, \\
& 0 \leq c^{\prime}(y) \leq 1, \\
& \int_{y_{-}}^{y_{+}} c(y) d F(y) \leq \bar{y} .
\end{aligned}
$$

In words, the schedule $c_{A}^{I B}($.$) is the best schedule for party A$ in the set of feasible schedules where all individuals with an income at most equal to the median income $y_{m}$ weakly prefer party $A$ 's schedule to $c_{B}^{o p t}($.$) . The intuition for why c_{A}^{I B}($.$) is the best$ schedule for party $A$ in that class runs as follows. Starting from $c_{A}^{I B}($.$) , if party A$ wants to increase the after-tax consumption level of individuals with income $y_{A}$, it necessarily has to give a little less income to people with income above $y_{A}^{\prime}$ (in order to satisfy the GBC; see Figure 2). But then, the proportion of people (weakly) preferring this tax schedule to $c_{B}^{\text {opt }}$ is strictly less than $50 \%$.

There is of course no reason to restrict a priori tax schemes to be such that the support for party $A$ is made exclusively of low income individuals. We also have to consider tax schedules where the support for any party is not an interval of voters. Observe first that, if a best response by party $A$ to $c_{B}^{\text {opt }}$ does not win the votes of all voters with income is below the median level $y_{m}$, then it must be of the "ends-againstthe-middle" form. A simple inspection of Figure 2, shows that, once $A$ 's policy crosses $c_{B}^{o p t}$, it must stay below (i.e., offer a lower consumption level than $c_{B}^{o p t}$ ) until it runs into the horizontal section of $c_{B}^{\text {opt }}$ (starting with some $y \geq y_{B}$ ), at which point it of course coincides with $c_{B}^{\text {opt }}$ (since giving more consumption than $c_{B}^{\text {opt }}$ would be a waste of money for party $A)$. We can then restrict the search for party $A^{\prime}$ best schedule to the set of schedules such that $c(y) \geq c_{B}^{o p t}$ for $y \in \Omega=\left[y_{-}, y_{1}\right] \cup\left[y_{A}^{\prime \prime}, y_{+}\right], y_{1}<y_{m}<y_{A}^{\prime \prime}$, where $H(\Omega)=1 / 2 \cdot{ }^{17}$ To do so, we proceed in two steps: we first set exogenously the threshold incomes $y_{1}$ and $y_{A}^{\prime \prime}$ such that $H(\Omega)=1 / 2$, and look for Party $A$ 's best schedule among

\footnotetext{
${ }^{17}$ It is straightforward that the constraint that $H(\Omega)$ is at least equal to one half is binding at the optimum, otherwise party $A$ could increase $c\left(y_{A}\right)$ while still satisfying its reelection constraint.
} 
those offering at least $c_{B}^{o p t}$ to all individuals in $\Omega$. Next, we optimize with respect to $y_{1}$ and $y_{A}^{\prime \prime}$ (keeping $H(\Omega)=1 / 2$ ) to find the tax schedule that maximizes party $A$ 's payoff. ${ }^{18}$

For given thresholds $y_{1}$ and $y_{A}^{\prime \prime}$ such that $H(\Omega)=1 / 2$, we define the following schedule (see Figure 2), denoted by $c_{A}^{I I B}(y)$, as: ${ }^{19}$

$$
c_{A}^{I I B}(y)=\left\{\begin{array}{l}
c_{B}^{o p t}(y)+I_{2}^{I I B} \text { if } y-\leq y \leq y_{A} \\
c_{A}^{I I B}\left(y_{A}\right) \text { if } y_{A}<y \leq \hat{y}_{A} \\
c_{B}^{o p t}(y) \text { if } \hat{y}_{A} \leq y \leq y_{1} \\
c_{A}^{I I B}\left(y_{1}\right) \text { if } y_{1}<y \leq \tilde{y}_{A} \\
c_{A}^{I I B}\left(\tilde{y}_{A}\right)+y-\tilde{y}_{A} \text { if } \tilde{y}_{A}<y \leq y_{A}^{\prime \prime} \\
c_{B}^{o p t}(y) \text { if } y_{A}^{\prime \prime} \leq y \leq y_{+}
\end{array}\right.
$$

The following proposition is established in Appendix C:

Proposition 3 Fix the set $\Omega=\left[y_{-}, y_{1}\right] \cup\left[y_{A}^{\prime \prime}, y_{+}\right]$where $y_{1}<y_{m}<y_{A}^{\prime \prime}$ and such that $H(\Omega)=1 / 2$. The function $c_{A}^{I I B}(y)$ is the solution to the following optimization program:

$$
\begin{aligned}
& \max c\left(y_{A}\right) \text { such that } \\
& y \in \Omega \Rightarrow c(y) \geq c_{B}^{o p t}(y), \\
& 0 \leq c^{\prime}(y) \leq 1, \\
& \int_{y_{-}}^{y_{+}} c(y) d F(y) \leq \bar{y} .
\end{aligned}
$$

Proposition 3 states that the function $c_{A}^{I I B}$ is party $A$ 's best response to $c_{B}^{\text {opt }}$ when the set of feasible tax schedules for $A$ is restricted to those giving at least the same consumption as $c_{B}^{\text {opt }}$ for the $50 \%$ of the polity belonging to the exogenous set $\Omega$. It is clear from the definition of $\Omega$ that there is a unidimensional family of $c_{A}^{I I B}$ functions associated with $\Omega$. In other words, by varying the value of (say) $y_{1}$ while choosing the value of $y_{A}^{\prime \prime}$ such that $H(\Omega)=1 / 2$, party $A$ can span the set of feasible tax functions guaranteeing reelection as defined by (9). Party $A$ then chooses the tax function that maximizes the value of $c\left(y_{A}\right){ }^{20}$

\footnotetext{
${ }^{18}$ We thank John Roemer for suggesting this proof strategy.

${ }^{19}$ Figure 2 is drawn for the case where $y_{1}<y_{A}^{\prime}$ and $c_{A}^{I I B}\left(y_{A}\right)<c_{A}^{I B}\left(y_{A}\right)$, but it is easy to draw the same Figure with $y_{1}=y_{A}^{\prime}$ and/or $c_{A}^{I I B}\left(y_{A}\right) \geq c_{A}^{I B}\left(y_{A}\right)$.

${ }^{20}$ For the formal statement of this optimization problem, see the working paper version referred to in footnote 15 .
} 
We now give, with the help of Figure 2, the intuition as to why this tax schedule is the best alternative to schedule $c_{A}^{I B}$. In order to maximize the consumption level offered to individuals with pre-tax income $y_{A}$, party $A$ has to propose a zero marginal tax rate to individuals with $y \leq y_{A}$ (negative marginal tax rates being prohibited). Since we are looking for a schedule that is not such that all below-median income agents vote for $A$, it must be the case that $c_{A}^{I I B}$ crosses $c_{B}^{\text {opt }}$ at some $y=y_{1}<y_{m}$. All individuals with $y \leq y_{1}$ then vote for party $A$. The least costly way to obtain the support of these voters is to tax those with $y_{A}<y<y_{1}$ at $100 \%$ at the margin, under the constraint that they receive at least as much as with $c_{B}^{o p t}$. That is, we have that $c_{A}^{I I B^{\prime}}(y)=0$ for $y_{A}<y<\hat{y}_{A}$ and $c_{A}^{I I B^{\prime}}(y)=1$ together with $c_{A}^{I I B}(y)=c_{B}^{o p t}(y)$ for $\hat{y}_{A}<y<y_{1}$. Since $y_{1}<y_{m}$, party $A$ needs the support of agents with income levels higher than $y_{B}$. Given our prohibition of negative marginal tax rates, it is impossible for party $A$ to garner the support of agents with income between $y_{1}$ and $y_{B}$. This means that there must exist an income level $y>y_{B}$, which we call $y_{A}^{\prime \prime}$, such that $c_{A}^{I I B}\left(y_{A}^{\prime \prime}\right)=c_{B}^{o p t}\left(y_{A}^{\prime \prime}\right)$. Given that $c_{B}^{o p t^{\prime}}(y)=0$ for $y \geq y_{B}$, we obtain that $c_{A}^{I I B}(y)=c_{B}^{o p t}(y)$ for all $y_{A}^{\prime \prime} \leq y \leq y_{+}$. Party $A$ chooses the values of $y_{1}$ and $y_{A}^{\prime \prime}$ in order to maximize $c_{A}^{I I B}\left(y_{A}\right)$ under the constraint that it gathers one half of the votes -i.e., that $\int_{y_{-}}^{y_{1}} d F+\int_{y_{A}^{\prime \prime}}^{y_{+}} d F=1 / 2$.

We have thus shown that, under Assumption 1 and when party $B$ plays $c_{B}^{\text {opt }}$, party $A$ 's $B P R$ is either $c_{A}^{I B}$ (where low income agents vote for party $A$ while high income voters support party $B$ ) or $c_{A}^{I I B}$ (an "ends-against-the-middle" situation, where low and high income voters support party $A$ while middle income agents vote for party $B$ ). To determine which of these two candidates effectively represents the party's best policy we simply have to compare the respective consumption levels they imply for its constituent (an individual with income $y_{A}$ ). We have that $c_{A}^{I B}$ is better when $c_{A}^{I B}\left(y_{A}\right)>c_{A}^{I I B}\left(y_{A}\right)$, while $c_{A}^{I I B}$ is better if the opposite relationship occurs. We summarize the results obtained in this section in the following Proposition.

Proposition 4 Under Assumption 1, if party B proposes its unconstrained most-preferred schedule $c_{B}^{\text {opt }}$, then party $A$ 's best response is to offer either $c_{A}^{I B}$ or $c_{A}^{I I B}$. In either case, (i) a subset of the population obtains the same after-tax income under the tax schedules 
proposed by both parties, and (ii) party $B$ has no incentive to deviate from $c_{B}^{\text {opt }}$.

\section{Party A proposes its unconstrained most-preferred pol- icy}

The analysis developed in this section parallels the one introduced in the previous section, except that the roles played by the two parties are reversed. We now assume that $A$ plays its unconstrained optimal strategy $T_{A}^{o p t}$. The corresponding after-tax schedule $c_{A}^{\text {opt }}$ is depicted on Figure 3. We assume that the reelection constraint is binding for party B when faced with $c_{A}^{o p t}$ (i.e., policy $c_{A}^{o p t}$ is preferred by a strict majority of voters to $c_{B}^{o p t}$ ), which translates into the following Assumption (the counterpart to Assumption $1)$ :

Assumption 2: $c_{A}^{\text {opt }}\left(y_{m}\right)>c_{B}^{o p t}\left(y_{m}\right)$.

Under Assumption 2, party $A$ is (re)elected for sure if it proposes $T_{A}^{o p t}$ (or equivalently $c_{A}^{o p t}$ ) while party $B$ enacts its constrained optimal policy once in office. Party $A$ then has no incentive to choose a schedule different from $c_{A}^{\text {opt }}$, and we construct party $B$ 's best response. As in the previous section, we start by constructing the best tax/consumption schedule satisfying pattern $I$ where only high income agents vote for party B. We then show that the only alternative to this schedule is an "end-against-themiddle" proposal belonging to pattern $I I$, where the poor and the rich support party $B$ while the middle class supports $A .^{21}$

We first construct a simple tax function that allows party $B$ to receive the votes of all individuals with an income above the median $y_{m}$. Party $B$ 's schedule is denoted by $c_{B}^{I A}$ and is constructed as follows (see Figure 3 ):

$$
c_{B}^{I A}(y)=\left\{\begin{array}{l}
y+I_{1}^{I A} \text { if } y_{-} \leq y \leq y_{m} \\
c_{A}^{o p t}(y) \text { if } y_{m}<y \leq y_{B}^{\prime} \\
c_{B}^{I A}\left(y_{B}^{\prime}\right)+y-y_{B}^{\prime} \text { if } y_{B}^{\prime} \leq y \leq y_{B} \\
c_{B}^{I A}\left(y_{B}\right) \text { if } y_{B} \leq y \leq y_{+}
\end{array}\right.
$$

All individuals with pre-tax income above $y_{B}$ face a marginal tax rate of one. Let $y_{B}^{\prime}$ denote the threshold income level such that (i) all individuals with income in between

\footnotetext{
${ }^{21}$ Observe the contrast with section 4 , where the middle class votes for party $B$ while the extremes support party $A$.
} 
$y_{m}$ and $y_{B}^{\prime}$ face a marginal tax rate of one while individuals with income in-between $y_{B}^{\prime}$ and $y_{B}$ face a zero marginal tax rate, and $(i i) c_{B}^{I A}(y)=c_{A}^{\text {opt }}(y)$ for the individuals whose income $y$ is between $y_{m}$ and $y_{B}^{\prime}$. Lower-than-median income individuals are faced with a zero marginal tax rate. It is easy to see that $c_{B}^{I A}($.$) is determined completely (see$ working paper version for a formal proof) by the value of $c_{B}^{I A}(0)$-i.e., by $I_{1}^{I A}-$ and we choose the value of $I_{1}^{I A}$ that is such that $c_{B}^{I A}($.$) integrates to the mean of the income$ distribution.

We now state the following proposition: ${ }^{22}$

Proposition 5 The function $c_{B}^{I A}(y)$ is the solution to the following optimization program:

$$
\begin{aligned}
& \max c\left(y_{B}\right) \text { such that } \\
& c(y) \geq c_{A}^{\text {opt }}(y) \text { for } y \geq y_{m}, \\
& 0 \leq c^{\prime}(y) \leq 1, \\
& \int_{y_{-}}^{y_{+}} c(y) d F(y) \leq \bar{y} .
\end{aligned}
$$

In words, the schedule $c_{B}^{I A}($.$) is the best feasible schedule for party B$ among all those where all individuals with an income larger than the median income $y_{m}$ weakly prefer party $B$ 's schedule to $c_{A}^{o p t}($.$) . The intuition for why c_{B}^{I A}($.$) is the best schedule for party$ $B$ in that class runs as follows. Starting from $c_{B}^{I A}($.$) , if party B$ wants to increase the after-tax consumption level of individuals with income $y_{B}$, it necessarily has to give more to all individuals with $y_{B}^{\prime} \leq y \leq y_{+}$, because of the prohibition of negative marginal tax rates. Because of the $\mathrm{GBC}$, it then has to give less consumption to some individuals with income lower than $y_{B}^{\prime}$, including individuals with $y<y_{m}$ (since marginal tax rate cannot exceed one). But then, the proportion of people (weakly) preferring this tax schedule to $c_{A}^{\text {opt }}$ is strictly less than $50 \%$.

There is of course no reason to restrict a priori tax schemes to be such that the support for party $B$ is made exclusively of high income individuals. An argument similar to the one developed in the previous section shows that any tax function by party $B$

\footnotetext{
${ }^{22}$ The proof follows closely the proof of Proposition 2 and is left to the reader.
} 
that is not supported by all voters with above-median income must be of the "endsagainst-the-middle" type. We then restrict the search for the best schedule by party $B$ to the set of schedules such that $c(y) \geq c_{B}^{o p t}$ for $y \in \Omega=\left[y_{-}, y_{B}^{\prime \prime}\right] \cup\left[y_{2}, y_{+}\right], y_{B}^{\prime \prime}<y_{m}<y_{2}$, where $H(\Omega)=1 / 2$. We proceed in the same two steps as in the previous section: we first set exogenously the threshold incomes $y_{B}^{\prime \prime}$ and $y_{2}$ such that $H(\Omega)=1 / 2$ and look for the best schedule for party $B$ among those offering at least $c_{A}^{o p t}$ to all individuals in $\Omega$. We then optimize with respect to $y_{B}^{\prime \prime}$ and $y_{2}$ (keeping $H(\Omega)=1 / 2$ ) to find the tax schedule that maximizes party $B$ 's payoff.

For given thresholds $y_{B}^{\prime \prime}$ and $y_{2}$ such that $H(\Omega)=1 / 2$, we define the following schedule (see Figure 3$),{ }^{23}$ denoted by $c_{B}^{I I A}(y)$ :

$$
c_{B}^{I I A}(y)=\left\{\begin{array}{l}
c_{A}^{o p t}(y) \text { if } y_{-} \leq y \leq y_{B}^{\prime \prime} \\
c_{B}^{I I A}\left(y_{B}^{\prime \prime}\right) \text { if } y_{B}^{\prime \prime}<y \leq \tilde{y}_{B} \\
c_{B}^{I I A}\left(\tilde{y}_{B}\right)+y-\tilde{y}_{B} \text { if } \tilde{y}_{B}<y \leq y_{2} \\
c_{A}^{o t}\left(y_{2}\right) \text { if } y_{2}<y \leq \hat{y}_{B} \\
c_{B}^{I I A}\left(\hat{y}_{B}\right)+y-\hat{y}_{B} \text { if } \hat{y}_{B}<y \leq y_{B} \\
c_{B}^{I I A}\left(y_{B}\right) \text { if } y_{B} \leq y \leq y_{+}
\end{array}\right.
$$

The proof of the following proposition follows closely the one of Proposition 3 and is left to the reader:

Proposition 6 Fix the set $\Omega=\left[y_{-}, y_{B}^{\prime \prime}\right] \cup\left[y_{2}, y_{+}\right], y_{B}^{\prime \prime}<y_{m}<y_{2}$, where $H(\Omega)=1 / 2$. The function $c_{B}^{I I A}(y)$ is the solution to the following optimization program:

$$
\begin{aligned}
& \max c\left(y_{B}\right) \text { such that } \\
& y \in \Omega \Rightarrow c(y) \geq c_{A}^{o p t}(y), \\
& 0 \leq c^{\prime}(y) \leq 1, \\
& \int_{y_{-}}^{y_{+}} c(y) d F(y) \leq \bar{y} .
\end{aligned}
$$

Proposition 6 states that the function $c_{B}^{I I A}$ is party $B$ 's best response to $c_{A}^{\text {opt }}$ when the set of feasible tax schedules for $B$ is restricted to those giving at least the same consumption as $c_{A}^{\text {opt }}$ for the voters whose income level belong to the exogenous set $\Omega$,

\footnotetext{
${ }^{23}$ Figure 3 is drawn for the case where $y_{2}<\hat{y}_{B}$ and $c_{B}^{I I A}\left(y_{B}\right)<c_{B}^{I A}\left(y_{B}\right)$, but it is easy to draw the same Figure with $y_{2}=\hat{y}_{B}$ and $/$ or $c_{B}^{I I A}\left(y_{B}\right) \geq c_{B}^{I A}\left(y_{B}\right)$.
} 
whose measure is one half. By the same argument as in the previous section, party $B$ chooses among the unidimensional set of policies $c_{B}^{I I A}$ (indexed for instance by $y_{B}^{\prime \prime}$ ) the one that maximizes $c\left(y_{B}\right)$.

We now give, with the help of Figure 3, the intuition as to why this tax schedule is the best alternative to schedule $c_{B}^{I A}$. In order to maximize the consumption level offered to individuals with pre-tax income $y_{B}$, party $B$ has to impose a $100 \%$ marginal tax rate on individuals with $y>y_{B}$ (larger marginal tax rates being prohibited). Since we are looking for a schedule that is not such that all above-median income agents vote for $B$, it must be the case that $c_{B}^{I I A}$ crosses $c_{A}^{\text {opt }}$ at some $y=y_{2}>y_{m}$ (with $c_{B}^{I I A}(y)<c_{A}^{\text {opt }}(y)$ for $y=y_{2}-\varepsilon$, for $\varepsilon$ arbitrarily small and positive). All individuals with $y \geq y_{2}$ then vote for party $B$. The least costly way to obtain the support of these voters is to tax those with $y_{2} \leq y \leq \hat{y}_{B}<y_{B}$ at $100 \%$ at the margin while giving them exactly the same consumption level than with $c_{B}^{\text {opt }}$, and to impose a zero marginal tax rate on individuals $\hat{y}_{B} \leq y<y_{B}$ (see Figure 3 ). Since $y_{2}>y_{m}$, party $B$ needs the support from agents with income levels lower than $y_{A}$. Given our prohibition of marginal tax rates larger than one, it is impossible for party $B$ to have the support of agents with income between $y_{A}$ and $y_{2}$. This means that there must exist an income level $y<y_{A}$, which we call $y_{B}^{\prime \prime}$, such that $c_{B}^{I I A}\left(y_{B}^{\prime \prime}\right)=c_{A}^{o p t}\left(y_{B}^{\prime \prime}\right)$. Given that $c_{A}^{o p t^{\prime}}(y)=1$ for $y<y_{A}$, we obtain that $c_{B}^{I I A}(y)=c_{A}^{o p t}(y)$ for all $y_{-} \leq y \leq y_{B}^{\prime \prime}$. Party $B$ chooses the values of $y_{2}$ and $y_{B}^{\prime \prime}$ in order to maximize $c_{B}^{I I A}\left(y_{B}\right)$ under the constraint that it gathers one half of the votes -i.e., that $\int_{y_{-}}^{y_{B}^{\prime \prime}} d F+\int_{y_{2}}^{y_{+}} d F=1 / 2$.

We have thus shown that, under Assumption 2 and when party $A$ plays $c_{A}^{\text {opt }}$, party $B$ 's $B P R$ is either $c_{B}^{I A}$ (where low income agents vote for party $A$ and high income voters support party $B$ ) or $c_{B}^{I I A}$ (an "ends-against-the-middle" situation, where low and high income voters support party $B$ while middle income agents vote for party $A$ ). To determine which of these two candidates effectively represents the party's best policy we simply have to compare the respective consumption levels they imply for its constituent (an individual with income $y_{B}$ ). We have that $c_{B}^{I A}$ is better when $c_{B}^{I A}\left(y_{A}\right)>c_{B}^{I I A}\left(y_{B}\right)$, while $c_{B}^{I I A}$ is better if the opposite relationship occurs. We summarize the results obtained in this section in the following proposition. 
Proposition 7 Under Assumption 2, if party A proposes its unconstrained most-preferred schedule $c_{A}^{\text {opt }}$, then party $B$ 's best response is to offer either $c_{B}^{I A}$ or $c_{B}^{I I A}$. In either case, (i) a subset of the population obtains the same after-tax income under the tax schedules proposed by both parties, and (ii) party $A$ has no incentive to deviate from $c_{A}^{\text {opt }}$.

So far we have characterized policy pairs that potentially constitute $B P R$ equilibria of the electoral game. In each case we have posited that one of the parties ( $B$ in Section 4 and $A$ in Section 5) was playing its unconstrained optimal policy. We have constructed two potential $B P R$ schedules for the other party. Determining the best of these two schedules implies a comparison of endogenous variables. The next section studies the circumstances under which the policy pairs described here and in the previous section effectively constitute a $B P R$ equilibrium. For this we provide conditions on the income levels $y_{A}$ and $y_{B}$ of the parties' respective constituents which are the fundamental exogenous variables underlying our analysis.

To make the argument crisper, some extra terminology is useful. An outcome will be referred to as "Type I" equilibrium when parties receive the support of either the poorer or the richer part of the electorate, while "Type II" equilibria are of the ends-againstthe-middle variety (one party receives the support of the poorer and richer voters while voters in the middle of the income distribution support the other party). We also index the equilibrium type by the identity of the party proposing its unconstrained optimal policy, to obtain the following definitions:

\section{Definition 1}

In a type $I_{A}$ equilibrium, party $A$ proposes $c_{A}^{o p t}$ while party $B$ proposes $c_{B}^{I A}$. In a type $I I_{A}$ equilibrium, party $A$ proposes $c_{A}^{o p t}$ while party $B$ proposes $c_{B}^{I I A}$.

In a type $I_{B}$ equilibrium, party $B$ proposes $c_{B}^{o p t}$ while party $A$ proposes $c_{A}^{I B}$. In a type $I I_{B}$ equilibrium, party $B$ proposes $c_{B}^{\text {opt }}$ while party $A$ proposes $c_{A}^{I I B}$.

\section{Equilibrium partition}

We are now in a position to state our main result. 
Proposition 8 The space $\left(y_{B}, y_{A}\right)$ can be partitioned into four regions, each corresponding to a different BPR equilibrium. There exist three decreasing functions of $y_{B}$, denoted by $\Phi_{A}, \Phi$ and $\Phi_{B}$, that are such that

$$
\begin{aligned}
& \text { if } y_{-} \leq y_{A} \leq \Phi_{B}\left(y_{B}\right) \text {, the equilibrium is of type } I I_{B} \text {; } \\
& \text { if } \Phi_{B}\left(y_{B}\right) \leq y_{A} \leq \Phi\left(y_{B}\right) \text {, the equilibrium is of type } I_{B} \text {; } \\
& \text { if } \Phi\left(y_{B}\right) \leq y_{A} \leq \Phi_{A}\left(y_{B}\right) \text {, the equilibrium is of type } I_{A} \text {; } \\
& \text { if } \Phi_{A}\left(y_{B}\right) \leq y_{A} \text {, the equilibrium is of type } I I_{A} \text {. }
\end{aligned}
$$

The three functions and the partition of equilibria they delineate are represented on Figure 4. The formal proof of Proposition 8 is provided in Appendix D. Here we restrict ourselves to presenting the underlying intuition.

If the median income individuals are indifferent between both parties' unconstrained most-preferred policies $\left(T_{A}^{o p t}\right.$ and $T_{B}^{o p t}$ ), then the unique equilibrium is such that each party proposes its unconstrained most-preferred policy. This is because under this policy any incumbent party will be reelected with one half of the votes. The locus of pairs $\left(y_{B}, y_{A}\right)$ for which this is true is represented by the function $y_{A}=\Phi\left(y_{B}\right)$. To the left of this schedule (in the $\left(y_{B}, y_{A}\right)$ space - see Figure 4), Assumption 1 holds so that by Proposition 7 and Definition 1 , the equilibrium of the game is of Type $I_{B}$ or $I I_{B}$; it is party $B$ who proposes its unconstrained optimal policy. Similarly, to the right of $\Phi$, Assumption 2 holds and, by Proposition 4 and Definition 1, the equilibrium of the game is of Type $I_{A}$ or $I I_{A}$, and it is party $A$ who proposes its unconstrained optimal policy.

Intuitively, we obtain that party $A$ proposes its unconstrained optimal policy (i.e., Assumption 2 holds) if $y_{B}$ is large enough (i.e., very different from $y_{m}$ ) for a given $y_{A}$, or if $y_{A}$ is large enough (i.e., close enough to $y_{m}$ ) for a given $y_{B}$. The proof of Proposition 8 also shows that the function $\Phi$ is decreasing in $y_{B} \cdot{ }^{24}$ This means that,

\footnotetext{
${ }^{24}$ To understand why $\Phi$ decreases with $y_{B}$, observe first that the space of most-preferred after-tax income schedules is unidimensional and can be indexed by the pre-tax income of the individual (since there is a unique kink in the most-preferred after-tax income function, with zero marginal tax rate below and unitary marginal tax rate above — see Figure 1). We show in the Appendix that individual preferences are single-peaked in the space of most-preferred policies. That is, the utility that an individual with gross income $y$ achieves with the most-preferred tax schedule of an individual with gross income $x$ increases with $x$ when $x<y$ and decreases with $x$ when $x>y$. This in turn implies that, as $y_{B}$ increases, the value of $y_{A}$ for which the median income individual is indifferent between the most-preferred policies of $y_{A}$ and $y_{B}$ decreases.
} 
the lower $y_{A}$ is (i.e., the more different it is from $y_{m}$ ), the larger (i.e., the more different from $\left.y_{m}\right) y_{B}$ has to be in order for party $A$ to propose its unconstrained optimal policy at equilibrium. In other words, the party with a moderate (i.e., close to the median) constituent offers its optimal unconstrained policy. Finally, we obtain that, if $y_{B}$ is large enough (close enough to the maximum income $y_{+}$), then whatever the value of $y_{A} \leq y_{m}$, the equilibrium is of type $I_{A}$ or $I I_{A} \cdot{ }^{25}$

We now turn to the policy offered by the party not playing its unconstrained mostpreferred policy at the equilibrium. We obtain from Proposition 8 and Figure 4 that policies that divide the electorate between poorer and richer voters (Type I) are played if the parties' constituents are close to the locus $y_{A}=\Phi\left(y_{B}\right)$ : the party that is more extreme offers a policy that satisfies its base and voters up to the median income level if its base is not too extreme, and an ends-against-the-middle policy if its constituent is very extreme (very far from the median). The intuition for this result comes from the observation that policies $c_{B}^{I A}$ and $c_{A}^{I B}$ respectively tend toward $c_{B}^{\text {opt }}$ and $c_{A}^{\text {opt }}$ when $y_{A}$ and $y_{B}$ become arbitrary close to $\Phi$. This is not the case for policies $c_{B}^{I I A}$ and $c_{A}^{I I B}$. For any point such that $y_{A}=\Phi\left(y_{B}\right)$, the only equilibrium consists in both parties offering their unconstrained optimal policy. As we move slightly away from $\Phi$ by, say increasing $y_{A}$, the schedule $c_{B}^{I A}$ remains very close to $c_{B}^{o p t}$ (while ensuring that party $B$ is reelected if it is the incumbent), and thus gives more utility to party $B$ 's constituents than the schedule $c_{B}^{I I A}$.

The fact that both $\Phi_{A}$ and $\Phi_{B}$ decrease with $y_{B}$ is intuitive once we look at Figure 4. We see that the locus $\Phi_{B}$ gives, for any value of $y_{A}$, the minimum value of $y_{B}$ that is compatible with a Type I equilibrium. Similarly, $\Phi_{A}$ gives, for values of $y_{A}$ large enough, the maximum value of $y_{B}$ compatible with a Type I equilibrium. In other words, $\Phi_{B}$ and $\Phi_{A}$ determine the boundaries of an interval of values of $y_{B}$ for which we have a Type I equilibrium. The fact that both functions $\Phi_{B}$ and $\Phi_{A}$ are decreasing

\footnotetext{
${ }^{25}$ This is due to the fact that the median income individual strictly prefers the unconstrained optimal tax schedule of party $A$ (whatever the value of $y_{A}<y_{m}$ ) to the one of party $B$ when $y_{B}$ is arbitrarily close to $y_{+}$. This preference in turn comes from the observation that, under any individual $y$ 's mostpreferred policy, all individuals with an income above $y$ obtain at least the average income $\bar{y}$. On the other hand, individual $y_{+}$'s most preferred policy is the laissez-faire, so that with a positively skewed income distribution the median income prefers the policy advocated by party $A$ to the laissez-faire.
} 
in $y_{B}$ means that this interval moves to the right (its two extreme values increase) as $y_{A}$ decreases. This is intuitive since the value of $y_{B}$ for which both parties play their unconstrained most-preferred policy also increases when $y_{A}$ decreases.

Finally, observe that there is some asymmetry in the model because of the assumption that the median income is lower than the mean. This asymmetry benefits party $A$ (whose constituent has a lower-than-median income) in the following sense: there exist equilibria where party $A$ proposes its unconstrained optimal policy even when $y_{A}$ is extreme (i.e., very low - provided of course that $y_{B}$ is also extreme, i.e., large enough) while there is no equilibrium where party $B$ proposes its unconstrained optimal policy when $y_{B}$ is extreme (i.e., large enough, whatever the value of $y_{A}$ ).

\section{Conclusion}

In this paper, we develop a repeated electoral competition game between two parties, each maximizing the utility of a different citizen. Citizens differ only according to their exogenous income level. Parties are unable to commit to any policy before the election; they choose a non-linear income tax schedule once elected. In each period, citizens cast a vote either for the incumbent or for the challenger.

We first show that there exist (pure strategy) subgame perfect equilibria where both parties choose the most-preferred tax schedule of their constituent subject to the constraint that they are reelected. We characterize a class of these (Best Policy with Reelection, or $B P R$ ) equilibria for which one of the two parties plays the unconstrained optimal tax schedule of its constituents. We obtain that tax schedules in such $B P R$ equilibria are always piecewise linear. We distinguish between four types of equilibria and show that the specific type that emerges depends on the income levels of the constituents of the two parties. The party whose constituent is more moderate offers its optimal unconstrained policy, while the other party proposes a policy that satisfies its constituent and voters up to the median income voter, or an "ends-against-the-middle" policy if its constituent is very extreme (very far from the median income level). All types of equilibria are such that both parties propose the same tax schedule for a subset of the population. 
How do these results relate to the income tax schedules observed in reality? Piecewise linearity is a very common feature in practice. It is worth emphasizing that we do not assume that tax functions have this property, but rather that we start from a much larger set of admissible non-linear functions and that we obtain piecewise linearity as a property of all tax functions proposed in $B P R$ equilibria. In all equilibria we consider, one party proposes a tax function with only two brackets while the other party proposes a tax function with more than two brackets. One way to generate more brackets at equilibrium would be to assume that parties represent more than one constituent (i.e. income level). We leave such an extension for future research.

We also obtain that, in all equilibria studied, one party proposes a tax function (with minimum marginal tax rate up to a threshold income level and the maximum marginal rate above) that exhibits both marginal and average progressivity. The tax function proposed by the other party may not be progressive (except for very specific combinations of $y_{A}$ and $\left.y_{B}\right)$. Marginal progressivity is a characteristic of many real world tax schedules and is notoriously difficult to obtain as a solution in an optimal taxation framework. Average progressivity, on the other hand, is an even more common characteristic of real world tax schedules but our setting offers just one of the many possible explanations (which include essentially the entire optimal income tax literature).

Finally, in all equilibria studied both parties propose the same tax schedule to a subset of the population. This characteristic of equilibrium tax schedules is also obtained by Roemer (2009) who studies the same economic environment and the same set of admissible tax functions but who develops another electoral competition game where parties can commit to electoral promises. Roemer (2009) also uses data on income taxation in the US from 1960 to 2004 to check whether both parties propose the same tax schedule for a subset of the population. Since parties do not compete by announcing precise tax schedules ${ }^{26}$ Roemer (2009) looks at major tax reforms, attributing the reform to the party of the President at the time of reform. The reform then becomes the status quo until a new reform is enacted. He can then attribute both the status quo legislation

\footnotetext{
${ }^{26}$ This observation is much more in line with the postelection politics approach developed here than with the preelection politics model developed in Roemer (2009).
} 
and the reform to political parties. He obtains that most reforms do not change the effective tax-and-transfer rates faced by the middle class. His empirical evidence then supports our type I equilibria, which have this characteristic. Roemer (2009) also argues empirically that the Democratic party is more supported by poorer voters while richer voters tend to favor the Republican party. This observation is also more in line with Type I equilibria than with ends-against-the-middle, Type II, equilibria. Interpreting both observations in the light of our model leads us to the conclusion that both US parties represent constituents whose income level is not too far from the median voter's income level.

Our paper admittedly falls short on several accounts. First, we restrict the set of equilibria to $B P R$ equilibria where one party proposes the most-preferred policy of its constituent, absent any electoral consideration. It would be worthwhile to look at non- $B P R$ equilibria in this setting.

Finally, incentive effects on the labor supply decision are absent from our model. Introducing a preference for leisure and thus a distortionary impact of income taxation would constitute an interesting extension. This would certainly yield less extreme results which would have a more realistic flavor. In particular marginal tax rates of one would no longer emerge and be replaced by the tax revenue maximizing rates (maximum of Laffer curve). 


\section{APPENDIX}

\section{A Proof of Proposition 1}

As stated in the text, we resort to the concepts of simple strategy profiles, initial path and punishments introduced by Abreu (1988). The initial path $Q^{0}$ is an infinite stream of one-period pairs of actions, one for each party in the case this party is the incumbent (a party not elected in period $t$ has no action to undertake in that period). We define

$$
Q^{0}=\left\{\left(T_{A}^{*}(.), T_{B}^{*}(.)\right),\left(T_{A}^{*}(.), T_{B}^{*}(.)\right),\left(T_{A}^{*}(.), T_{B}^{*}(.)\right), \ldots\right\}
$$

The punishments are given by the following infinite stream of one-period pairs of actions. The punishment if party $A$ deviates is given by

$$
Q^{A}=\left\{\left(T_{A}^{o p t}(.), T_{B}^{*}(.)\right),\left(T_{A}^{o p t}(.), T_{B}^{*}(.)\right),\left(T_{A}^{o p t}(.), T_{B}^{*}(.)\right), \ldots\right\}
$$

while the punishment if party $B$ deviates is given by

$$
Q^{B}=\left\{\left(T_{A}^{*}(.), T_{B}^{o p t}(.)\right),\left(T_{A}^{*}(.), T_{B}^{o p t}(.)\right),\left(T_{A}^{*}(.), T_{B}^{o p t}(.)\right), \ldots\right\} .
$$

The prescription for each party is to play $Q^{0}$ if both parties have always followed $Q^{0}$ in the past and to play the punishment $Q^{i}$ if player $i$ has just deviated from $Q^{0}$. Also, parties have to keep playing the punishment for ever after party $i$ has deviated from $Q^{0}$, say in period $t$ : if party $j(j=i$ or $j \neq i)$ deviates from the punishment at date $k \geq t$, then both parties have to play $Q^{j}$ for ever starting at $k+1$.

If the history of the vote at time $t$ is consistent with both parties having played $Q^{0}$ in all periods, voters assume that players continue to play according to $Q^{0}$, so that $A$ if elected will implement $T_{A}^{*}($.$) while B$ will implement $T_{B}^{*}($.$) if elected. If the history$ is such that party $i$ has just deviated from its prescribed action (as described above), then voters anticipate that parties will follow $Q^{i}$ from now on. In all cases, citizens use these beliefs to compute the continuation value of each party and they vote for the party offering the highest continuation value.

Assume that both parties have followed the prescribed strategy $Q^{0}$ up to period $t$, and that party $A$ is the incumbent. By abiding by strategy $Q^{0}$ now and in the future, 
party $A$ remains in office for ever (since voters identify a vote for party $A$ as a vote for $T_{A}^{*}($.$) and a vote for B$ as a vote for $T_{B}^{*}($.$) , and since T_{A}^{*}($.$) is by definition the best$ policy that guarantees reelection for party $A$ when faced with the alternative $\left.T_{B}^{*}().\right)$ and obtains the payoff:

$$
(1-\delta) \sum_{\tau=t}^{\infty} \delta^{\tau-t}\left[v\left(y_{A}, T_{A}^{*}\left(y_{A}\right)\right)+\beta\right]=v\left(y_{A}, T_{A}^{*}\left(y_{A}\right)\right)+\beta .
$$

As explained in the text, Abreu (1988, Proposition 1) states that the subgame perfection of the simple strategy profile generated by $\left(Q^{0}, Q^{A}, Q^{B}\right)$ may be verified by checking "one-shot" deviations alone (i.e., deviations followed by conformity with the strategy profile in question). Voters gain nothing by deviating from their strategy (voting for the party offering them the highest continuation value, computed as explained above) since, with a continuum of voters, no single voter is decisive.

Assume for the moment that $T_{A}^{*}(.) \neq T_{A}^{o p t}($.$) and that T_{B}^{*}(.) \neq T_{B}^{o p t}($.$) . By definition$ of $T_{B}^{*}$, it must be the case that a majority of voters prefer $T_{A}^{*}$ to $T_{B}^{o p t}$ (or else, we would have that $T_{B}^{*}=T_{B}^{o p t}$ ), ensuring that party $A$ is elected at each round with the punishment $Q^{B}$. Likewise, we have that a majority of voters prefer $T_{B}^{*}$ to $T_{A}^{\text {opt }}$ (or else, we would have that $T_{A}^{*}=T_{A}^{\text {opt }}$ ), ensuring that party $B$ is elected at each round with the punishment $Q^{A}$.

Consider first the possibility of a one-shot deviation from $Q^{0}$ by $A$. Party $A$ may only deviate at any given stage if it is the current incumbent. According to the strategies defined above, party $A$ anticipates that both parties will play $Q^{A}$ after a deviation, which means (given voters' anticipations) that it will never be reelected again in the future and will have to face the policy $T_{B}^{*}($.$) for ever. Faced with this prospect, party A$ if it deviates chooses to implement its optimal unconstrained policy, $T_{A}^{o p t}($.$) . The payoff$ of $A$ following the deviation is thus given by

$$
\begin{aligned}
& (1-\delta)\left(v\left(y_{A}, T_{A}^{o p t}\left(y_{A}\right)\right)+\beta\right)+(1-\delta) \sum_{t=2}^{\infty} \delta^{t-1} v\left(y_{A}, T_{B}^{*}\left(y_{A}\right)\right) \\
& =(1-\delta)\left(v\left(y_{A}, T_{A}^{o p t}\left(y_{A}\right)\right)+\beta\right)+\delta v\left(y_{A}, T_{B}^{*}\left(y_{A}\right)\right)
\end{aligned}
$$

Comparing the payoffs associated with the initial path $Q^{0},(13)$, with that achieved in 
case of a deviation (14), shows that $A$ should remain on the initial path if and only if

$$
\delta \geq \frac{v\left(y_{A}, T_{A}^{o p t}\left(y_{A}\right)\right)-v\left(y_{A}, T_{A}^{*}\left(y_{A}\right)\right)}{v\left(y_{A}, T_{A}^{o p t}\left(y_{A}\right)\right)-v\left(y_{A}, T_{B}^{*}\left(y_{A}\right)\right)+\beta},
$$

i.e., if party $A$ is patient enough. Note that the right hand side of (15) is strictly lower than one if $v\left(y_{A}, T_{A}^{*}\left(y_{A}\right)\right)+\beta>v\left(y_{A}, T_{B}^{*}\left(y_{A}\right)\right)-$ i.e., if party $A$ is better off in office with its optimal constrained policy than out of office with the optimal constrained policy of the other party, a condition that is always satisfied (for any $\beta \geq 0$ ).

We now have to check that party $B$ has no incentive to deviate from the punishment path $Q^{A}$. When sticking to the policy choice implied by $Q^{A}, B$ obtains the payoff:

$$
(1-\delta) \sum_{\tau=t}^{\infty} \delta^{\tau-t}\left[v\left(y_{B}, T_{B}^{*}\left(y_{B}\right)\right)+\beta\right]=v\left(y_{B}, T_{B}^{*}\left(y_{B}\right)\right)+\beta .
$$

It if it deviates from $Q^{A}, B$ is punished in all subsequent periods according to $Q^{B}$ and gets the following continuation value:

$$
(1-\delta)\left(v\left(y_{B}, T_{B}^{o p t}\left(y_{B}\right)\right)+\beta\right)+\delta v\left(y_{B}, T_{A}^{*}\left(y_{B}\right)\right)
$$

Comparing the two previous expressions, $B$ should not deviate when

$$
\delta \geq \frac{v\left(y_{B}, T_{B}^{o p t}\left(y_{B}\right)\right)-v\left(y_{B}, T_{B}^{*}\left(y_{B}\right)\right)}{v\left(y_{B}, T_{B}^{o p t}\left(y_{B}\right)\right)-v\left(y_{B}, T_{A}^{*}\left(y_{B}\right)\right)+\beta} .
$$

The right hand side of (16) is strictly lower than one if $v\left(y_{B}, T_{B}^{*}\left(y_{B}\right)\right)+\beta>v\left(y_{B}, T_{A}^{*}\left(y_{B}\right)\right)-$ i.e., if party $B$ is better off in office with its optimal constrained policy than out of office with the optimal constrained policy of the other party, a condition that is always satisfied (for any $\beta \geq 0$ ).

Observe now that the inequality that must be satisfied for party $B$ not to have an incentive to deviate from the initial path $Q^{0}$ is the same as (16) - i.e., the inequality that guarantees that party $B$ abides by the punishment path $Q^{A}$. In both cases, party $B$ remains for ever in office with its optimal constrained policy if it follows the prescribed actions, with the punishment for a deviation being the same since it is given by $Q^{B}$ in both cases. Likewise, the inequality that must be satisfied for party $A$ to abide by $Q^{B}$ 
is (as given by (15)), the same as the one that is required for the same party to follow the initial path $Q^{0}{ }^{27}$

We have assumed up to now that $T_{A}^{*}(.) \neq T_{A}^{o p t}($.$) and that T_{B}^{*}(.) \neq T_{B}^{o p t}($.$) . Suppose$ now that $T_{A}^{*}()=.T_{A}^{o p t}($.$) while T_{B}^{*}(.) \neq T_{B}^{o p t}($.$) , so that the punishment paths are given$ by

$$
\begin{aligned}
Q^{A} & =\left\{\left(T_{A}^{o p t}(.), T_{B}^{*}(.)\right),\left(T_{A}^{o p t}(.), T_{B}^{*}(.)\right),\left(T_{A}^{o p t}(.), T_{B}^{*}(.)\right), \ldots\right\}, \\
Q^{B} & =\left\{\left(T_{A}^{o p t}(.), T_{B}^{o p t}(.)\right),\left(T_{A}^{o p t}(.), T_{B}^{o p t}(.)\right),\left(T_{A}^{o p t}(.), T_{B}^{o p t}(.)\right), \ldots\right\} .
\end{aligned}
$$

Party $A$ wins with its optimal unconstrained policy under both $Q^{0}$ and $Q^{A}$ and has thus no incentive to deviate from either. As for $Q^{B}$, a majority of voters must favor $T_{A}^{o p t}$ to $T_{B}^{o p t}$, or else we would have that $T_{B}^{*}=T_{o p t}^{B}$. Party $A$ thus has no incentive to deviate from $Q^{B}$. Party $B$ has no incentive to deviate from $Q^{A}$ if

$$
\delta \geq \frac{v\left(y_{B}, T_{B}^{o p t}\left(y_{B}\right)\right)-v\left(y_{B}, T_{B}^{*}\left(y_{B}\right)\right)}{v\left(y_{B}, T_{B}^{o p t}\left(y_{B}\right)\right)-v\left(y_{B}, T_{A}^{o p t}\left(y_{B}\right)\right)+\beta},
$$

whose right hand side is strictly lower than one since $v\left(y_{B}, T_{B}^{*}\left(y_{B}\right)\right)+\beta>v\left(y_{B}, T_{A}^{o p t}\left(y_{B}\right)\right)$ for any $\beta \geq 0$. This same equation also guarantees that party $B$ won't deviate from the initial path $Q^{0}$ (and also from $Q^{A}$, in the out-of-equilibrium situation where $B$ returns to power while both parties play $\left.Q^{A}\right)$.

We can deal similarly with the situation where $T_{B}^{*}()=.T_{B}^{o p t}($.$) , whether or not$ $T_{A}^{*}(.) \neq T_{A}^{o p t}($.$) .$

We then obtain that there exists a $B P R$ (subgame perfect) equilibrium as described in Proposition 1 provided that

$\delta \geq \tilde{\delta} \equiv \max \left\{\frac{v\left(y_{A}, T_{A}^{o p t}\left(y_{A}\right)\right)-v\left(y_{A}, T_{A}^{*}\left(y_{A}\right)\right)}{v\left(y_{A}, T_{A}^{o p t}\left(y_{A}\right)\right)-v\left(y_{A}, T_{B}^{*}\left(y_{A}\right)\right)+\beta}, \frac{v\left(y_{B}, T_{B}^{o p t}\left(y_{B}\right)\right)-v\left(y_{B}, T_{B}^{*}\left(y_{B}\right)\right)}{v\left(y_{B}, T_{B}^{o p t}\left(y_{B}\right)\right)-v\left(y_{B}, T_{A}^{*}\left(y_{B}\right)\right)+\beta}\right\}$,

with $0<\tilde{\delta}<1$.

\footnotetext{
${ }^{27}$ Party $i$ has no opportunity to deviate from punishment $Q^{i}(i=A, B)$ since it is never in power according to this punishment. Observe also that, even if party $i$ somehow managed to be elected while the other party correctly plays $Q^{i}$ (an out-of-equilibrium situation), it would definitely play $T_{i}^{o p t}$, which is the policy prescribed by punishment $Q^{i}$.
} 


\section{B Proof of Proposition 2}

The proof is by contradiction. Assume that $c_{A}^{I B}(y)$ does not solve the optimization program (8), but rather that the function $c^{*}(y)$ does. Define $g(y)=c^{*}(y)-c_{A}^{I B}(y)$, and consider the convex combination $(1-\varepsilon) c_{A}^{I B}(y)+\varepsilon c^{*}(y)=c_{A}^{I B}\left(y_{A}\right)+\varepsilon g\left(y_{A}\right)$, which is also feasible for program (8).

Define

$$
\begin{aligned}
\Delta(\varepsilon)= & c_{A}^{I B}\left(y_{A}\right)+\varepsilon g\left(y_{A}\right) \\
& -\int_{y_{-}}^{y_{A}} \varepsilon g^{\prime}(y) \beta(y) d y+\int_{y_{A}}^{y_{A}^{\prime}} \varepsilon g^{\prime}(y) \gamma(y) d y \\
& -\int_{y_{A}^{\prime}}^{y_{m}} \varepsilon g^{\prime}(y) \delta(y) d y+\int_{y_{m}}^{y_{+}} \varepsilon g^{\prime}(y) \alpha(y) d y \\
& +\int_{y_{A}^{\prime}}^{y_{m}}\left(c_{A}^{I B}(y)+\varepsilon g(y)-c_{B}^{o p t}(y)\right) \eta(y) d y \\
& +\rho\left[\bar{y}-\int_{y_{-}}^{y_{+}}\left(c_{A}^{I B}(y)+\varepsilon g(y)\right) d F(y)\right],
\end{aligned}
$$

where $\alpha(y), \beta(y), \delta(y), \gamma(y), \eta(y)$ are non-negative functions and $\rho$ is a non-negative number.

Observe that $\Delta$ is linear in $\varepsilon$, with $\Delta(0)$ corresponding to program (8) with $c_{A}^{I B}($.$) ,$ and with $\Delta(1)$ corresponding to program (8) with $c^{*}($.$) , plus a series of non-negative$ terms: for instance, in the intervals $\left[y_{-}, y_{A}\right]$ and $\left[y_{A}^{\prime}, y_{m}\right], g^{\prime} \leq 0$ because $c_{A}^{I B \prime}(y)=1$.

Suppose that we can find $\alpha(y), \beta(y), \delta(y), \gamma(y), \eta(y)$ and $\rho$ (all non-negative) such that $\Delta^{\prime}(0) \leq 0$. Since $\Delta$ is a linear function of $\varepsilon$, it will follow that $\Delta(0) \geq \Delta(1)$, which implies a fortiori that program (8) is maximized with $c_{A}^{I B}($.$) , our desired contradiction.$

We then assume that

$$
\begin{aligned}
\Delta^{\prime}(0)= & g\left(y_{A}\right)-\int_{y_{-}}^{y_{A}} g^{\prime}(y) \beta(y) d y+\int_{y_{A}}^{y_{A}^{\prime}} g^{\prime}(y) \gamma(y) d y \\
& -\int_{y_{A}^{\prime}}^{y_{m}} g^{\prime}(y) \delta(y) d y+\int_{y_{m}}^{y_{+}} g^{\prime}(y) \alpha(y) d y \\
& +\int_{y_{A}^{\prime}}^{y_{m}} g(y) \eta(y) d y-\rho \int_{y_{-}}^{y_{+}} g(y) d F(y) \\
\leq & 0 .
\end{aligned}
$$


Integrating by parts, we obtain

$$
\begin{aligned}
\Delta^{\prime}(0)= & g\left(y_{A}\right)-[g(y) \beta(y)]_{y_{-}}^{y_{A}}+\int_{y_{-}}^{y_{A}} g(y) \beta^{\prime}(y) d y \\
& +[g(y) \gamma(y)]_{y_{A}}^{y_{A}^{\prime}}-\int_{y_{A}}^{y_{A}^{\prime}} g(y) \gamma^{\prime}(y) d y \\
& -[g(y) \delta(y)]_{y_{A}^{\prime}}^{y_{m}}+\int_{y_{A}^{\prime}}^{y_{m}} g(y) \delta^{\prime}(y) d y \\
& +[g(y) \alpha(y)]_{y_{m}}^{y_{+}}-\int_{y_{m}}^{y_{+}} g(y) \alpha^{\prime}(y) d y \\
& +\int_{y_{A}^{\prime}}^{y_{m}} g(y) \eta(y) d y-\rho \int_{y_{-}}^{y_{+}} g(y) d F(y) \\
\leq & 0,
\end{aligned}
$$

which simplifies to

$$
\begin{aligned}
\Delta^{\prime}(0)= & g\left(y_{A}\right) \\
& -g\left(y_{A}\right) \beta\left(y_{A}\right)+g\left(y_{-}\right) \beta\left(y_{-}\right)+\int_{y_{-}}^{y_{A}}\left[\beta^{\prime}(y)-\rho f(y)\right] g(y) d y \\
& +g\left(y_{A}^{\prime}\right) \gamma\left(y_{A}^{\prime}\right)-g\left(y_{A}\right) \gamma\left(y_{A}\right)+\int_{y_{A}}^{y_{A}^{\prime}}\left[-\gamma^{\prime}(y)-\rho f(y)\right] g(y) d y \\
& -g\left(y_{m}\right) \delta\left(y_{m}\right)+g\left(y_{A}^{\prime}\right) \delta\left(y_{A}^{\prime}\right)+\int_{y_{A}^{\prime}}^{y_{m}}\left[\delta^{\prime}(y)+\eta(y)-\rho f(y)\right] g(y) d y \\
& +g\left(y_{+}\right) \alpha\left(y_{+}\right)-g\left(y_{m}\right) \alpha\left(y_{m}\right)+\int_{y_{m}}^{y_{+}}\left[-\alpha^{\prime}(y)-\rho f(y)\right] g(y) d y \\
\leq & 0 .
\end{aligned}
$$


Regrouping terms, we have

$$
\begin{aligned}
\Delta^{\prime}(0)= & g\left(y_{A}\right)\left(1-\beta\left(y_{A}\right)-\gamma\left(y_{A}\right)\right) \\
& +g\left(y_{A}^{\prime}\right)\left(\gamma\left(y_{A}^{\prime}\right)+\delta\left(y_{A}^{\prime}\right)\right) \\
& -g\left(y_{m}\right)\left(\alpha\left(y_{m}\right)+\delta\left(y_{m}\right)\right) \\
& +g\left(y_{-}\right) \beta\left(y_{-}\right)+g\left(y_{+}\right) \alpha\left(y_{+}\right) \\
& +\int_{y_{-}}^{y_{A}}\left[\beta^{\prime}(y)-\rho f(y)\right] g(y) d y \\
& +\int_{y_{A}}^{y_{A}^{\prime}}\left[-\gamma^{\prime}(y)-\rho f(y)\right] g(y) d y \\
& +\int_{y_{A}^{\prime}}^{y_{m}}\left[\delta^{\prime}(y)+\eta(y)-\rho f(y)\right] g(y) d y \\
& +\int_{y_{m}}^{y_{+}}\left[-\alpha^{\prime}(y)-\rho f(y)\right] g(y) d y \\
\leq & 0 .
\end{aligned}
$$

We can make sure that $\Delta^{\prime}(0) \leq 0$ if the Lagrangian functions and multipliers are chosen to satisfy the following inequalities:

$$
\begin{aligned}
& \beta\left(y_{A}\right)+\gamma\left(y_{A}\right) \geq 1, \\
& \gamma\left(y_{A}^{\prime}\right)+\delta\left(y_{A}^{\prime}\right) \leq 0 \\
& \alpha\left(y_{m}\right)+\delta\left(y_{m}\right) \geq 0 \\
& \beta\left(y_{-}\right) \leq 0 \\
& \alpha\left(y_{+}\right) \leq 0 \\
& \beta^{\prime}(y) \leq \rho f(y) \text { on }\left[y_{-}, y_{A}\right] \Rightarrow \beta\left(y_{A}\right)-\beta\left(y_{-}\right) \leq \rho F\left(y_{A}\right), \\
& \gamma^{\prime}(y) \geq-\rho f(y) \text { on }\left[y_{A}, y_{A}^{\prime}\right] \Rightarrow \gamma\left(y_{A}^{\prime}\right)-\gamma\left(y_{A}\right) \geq-\rho\left(F\left(y_{A}^{\prime}\right)-F\left(y_{A}\right)\right), \\
& \delta^{\prime}(y) \leq \rho f(y)-\eta(y) \text { on }\left[y_{A}^{\prime}, y_{m}\right] \Rightarrow \delta\left(y_{m}\right)-\delta\left(y_{A}^{\prime}\right) \leq \rho\left(1 / 2-F\left(y_{A}^{\prime}\right)\right)-\Gamma\left(y_{m}\right), \\
& \alpha^{\prime}(y) \geq-\rho f(y) \text { on }\left[y_{m}, y_{+}\right] \Rightarrow \alpha\left(y_{+}\right)-\alpha\left(y_{m}\right) \geq-\rho / 2,
\end{aligned}
$$

where

$$
\Gamma\left(y_{m}\right)=\int_{y_{A}^{\prime}}^{y_{m}} \eta(y) d y
$$


We must find non-negative functions $\alpha(y), \beta(y), \delta(y), \gamma(y), \eta(y)$ and a non-negative number $\rho$ satisfying those inequalities. Immediately, we deduce from (18) that $\gamma\left(y_{A}^{\prime}\right)=$ $\delta\left(y_{A}^{\prime}\right)=\beta\left(y_{-}\right)=\alpha\left(y_{+}\right)=0$.

We simplify and obtain the following system of 6 equations in 6 unknowns,

$$
\begin{aligned}
& \beta\left(y_{A}\right)+\gamma\left(y_{A}\right)=1, \\
& \alpha\left(y_{m}\right)+\delta\left(y_{m}\right)>0, \\
& \beta\left(y_{A}\right)=\rho F\left(y_{A}\right), \\
& \gamma\left(y_{A}\right)=\rho\left(F\left(y_{A}^{\prime}\right)-F\left(y_{A}\right)\right), \\
& \delta\left(y_{m}\right)=\rho\left(1 / 2-F\left(y_{A}^{\prime}\right)\right)-\Gamma\left(y_{m}\right), \\
& \alpha\left(y_{m}\right)=\rho / 2,
\end{aligned}
$$

where all inequalities have been replaced by an equal sign, except for (20) where we use a strict inequality. ${ }^{28}$

Using (21) and (22) in (19), we obtain that

$$
\begin{aligned}
\rho F\left(y_{A}\right)+\rho\left(F\left(y_{A}^{\prime}\right)-F\left(y_{A}\right)\right) & =1, \\
& \Rightarrow \rho F\left(y_{A}^{\prime}\right)=1 \\
& \Rightarrow \rho=1 / F\left(y_{A}^{\prime}\right) \geq 2 .
\end{aligned}
$$

Then (21) gives

$$
\left.\left.\beta\left(y_{A}\right)=\frac{F\left(y_{A}\right)}{F\left(y_{A}^{\prime}\right)} \in\right] 0,1\right]
$$

while (22) gives

$$
\gamma\left(y_{A}\right)=\frac{F\left(y_{A}^{\prime}\right)-F\left(y_{A}\right)}{F\left(y_{A}^{\prime}\right)} \in[0,1[
$$

and (24) gives

$$
\alpha\left(y_{m}\right)=\frac{1}{2 F\left(y_{A}^{\prime}\right)} \geq 1
$$

From (23), we have

$$
\delta\left(y_{m}\right)=\frac{1 / 2-F\left(y_{A}^{\prime}\right)}{F\left(y_{A}^{\prime}\right)}-\Gamma\left(y_{m}\right)
$$

\footnotetext{
${ }^{28}$ The inequality in (20) has to be strict. Otherwise, using (20) and (24) we would obtain that $\rho=0$, a contradiction with what follows.
} 
so that we can choose

$$
\Gamma\left(y_{m}\right)=\frac{1 / 2-F\left(y_{A}^{\prime}\right)}{F\left(y_{A}^{\prime}\right)} \geq 0 \text { and } \delta\left(y_{m}\right)=0
$$

and from (20) we obtain

$$
\alpha\left(y_{m}\right)+\delta\left(y_{m}\right)=\frac{1}{2 F\left(y_{A}^{\prime}\right)} \geq 1
$$

From the sign of derivatives of the functions $\alpha(y), \beta(y), \delta(y), \gamma(y)$ and $\eta(y)$ we can then immediately verify that they are non-negative in their intervals when end points are defined as above, meaning that we have indeed constructed non-negative Lagrangian functions, and proved our claim.

\section{Proof of Proposition 3}

The proof is by contradiction. Assume that $c_{A}^{I I B}(y)$ does not solve the optimization program (10), but rather that the function $c^{*}(y)$ does. Define $g(y)=c^{*}(y)-c_{A}^{I I B}(y)$, and consider the convex combination $(1-\varepsilon) c_{A}^{I I B}(y)+\varepsilon c^{*}(y)=c_{A}^{I I B}\left(y_{A}\right)+\varepsilon g\left(y_{A}\right)$, which is also feasible for program (10).

Define

$$
\begin{aligned}
\Delta(\varepsilon)= & c_{A}^{I I B}\left(y_{A}\right)+\varepsilon g\left(y_{A}\right) \\
& -\int_{y_{-}}^{y_{A}} \varepsilon g^{\prime}(y) \beta(y) d y+\int_{y_{A}}^{\hat{y}_{A}} \varepsilon g^{\prime}(y) \gamma(y) d y \\
& -\int_{\hat{y}_{A}}^{y_{1}} \varepsilon g^{\prime}(y) \delta(y) d y+\int_{y_{1}}^{\tilde{y}_{A}} \varepsilon g^{\prime}(y) \alpha(y) d y \\
& -\int_{\tilde{y}_{A}}^{y_{A}^{\prime \prime}} \varepsilon g^{\prime}(y) \eta(y) d y+\int_{y_{A}^{\prime \prime}}^{y_{+}} \varepsilon g^{\prime}(y) \theta(y) d y \\
& +\int_{\hat{y}_{A}}^{y_{1}}\left(c_{A}^{I I B}(y)+\varepsilon g(y)-c_{B}^{o p t}(y)\right) \lambda_{1}(y) d y \\
& +\int_{y_{A}^{\prime \prime}}^{y_{+}}\left(c_{A}^{I I B}(y)+\varepsilon g(y)-c_{B}^{o p t}(y)\right) \lambda_{2}(y) d y \\
& +\rho\left[\bar{y}-\int_{y_{-}}^{y_{+}}\left(c_{A}^{I I B}(y)+\varepsilon g(y)\right) d F(y)\right],
\end{aligned}
$$

where $\alpha(y), \beta(y), \delta(y), \gamma(y), \eta(y), \theta(y), \lambda_{1}(y)$ and $\lambda_{2}(y)$ are non-negative functions while $\rho$ is a non-negative number. 
Observe that $\Delta$ is linear in $\varepsilon$, with $\Delta(0)$ corresponding to program (10) with $c_{A}^{I I B}($.$) ,$ and with $\Delta(1)$ corresponding to program (10) with $c^{*}($.$) , plus a series of non-negative$ terms: for instance, in the intervals $\left[y_{-}, y_{A}\right]$ and $\left[\hat{y}_{A}, y_{1}\right], g^{\prime} \leq 0$ because $c_{A}^{I I B \prime}(y)=1$.

Suppose that we can find $\alpha(y), \beta(y), \delta(y), \gamma(y), \eta(y), \theta(y), \lambda_{1}(y), \lambda_{2}(y)$ and $\rho$ (all non-negative) such that $\Delta^{\prime}(0) \leq 0$. Since $\Delta$ is a linear function of $\varepsilon$, it will follow that $\Delta(0) \geq \Delta(1)$, which implies a fortiori that program (10) is maximized with $c_{A}^{I I B}($.$) , our$ desired contradiction.

We then assume that

$$
\begin{aligned}
\Delta^{\prime}(0)= & g\left(y_{A}\right)-\int_{y_{-}}^{y_{A}} g^{\prime}(y) \beta(y) d y+\int_{y_{A}}^{\hat{y}_{A}} g^{\prime}(y) \gamma(y) d y \\
& -\int_{\hat{y}_{A}}^{y_{1}} g^{\prime}(y) \delta(y) d y+\int_{y_{1}}^{\tilde{y}_{A}} g^{\prime}(y) \alpha(y) d y \\
& -\int_{\tilde{y}_{A}}^{y_{A}^{\prime \prime}} g^{\prime}(y) \eta(y) d y+\int_{y_{A}^{\prime \prime}}^{y_{+}} g^{\prime}(y) \theta(y) d y \\
& +\int_{\hat{y}_{A}}^{y_{1}} g(y) \lambda_{1}(y) d y+\int_{y_{A}^{\prime \prime}}^{y_{+}} g(y) \lambda_{2}(y) d y \\
& -\rho \int_{y_{-}}^{y_{+}} g(y) d F(y) \\
\leq & 0 .
\end{aligned}
$$

Integrating by parts, we obtain

$$
\begin{aligned}
\Delta^{\prime}(0)= & g\left(y_{A}\right)-[g(y) \beta(y)]_{y_{-}}^{y_{A}}+\int_{y_{-}}^{y_{A}} g(y) \beta^{\prime}(y) d y \\
& +[g(y) \gamma(y)]_{y_{A}}^{\hat{y}_{A}}-\int_{y_{A}}^{y_{A}} g(y) \gamma^{\prime}(y) d y \\
& -[g(y) \delta(y)]_{\hat{y}_{A}}^{y_{1}}+\int_{\hat{y}_{A}}^{y_{1}} g(y) \delta^{\prime}(y) d y \\
& +[g(y) \alpha(y)]_{y_{1}}^{\tilde{y}_{A}}-\int_{y_{1}}^{\tilde{y}_{A}} g(y) \alpha^{\prime}(y) d y \\
& -[g(y) \eta(y)]_{\tilde{y}_{A}}^{y_{A}^{\prime \prime}}+\int_{\tilde{y}_{A}}^{y_{A}^{\prime \prime}} g(y) \eta^{\prime}(y) d y \\
& +[g(y) \theta(y)]_{y_{A}^{\prime \prime}}^{y_{+}}-\int_{y_{A}^{\prime \prime}}^{y_{+}} g(y) \theta^{\prime}(y) d y \\
& +\int_{\hat{y}_{A}}^{y_{1}} g(y) \lambda_{1}(y) d y+\int_{y_{A}^{\prime \prime}}^{y_{+}} g(y) \lambda_{2}(y) d y-\rho \int_{y_{-}}^{y_{+}} g(y) d F(y) \\
\leq & 0,
\end{aligned}
$$


which simplifies to

$$
\begin{aligned}
\Delta^{\prime}(0)= & g\left(y_{A}\right) \\
& -g\left(y_{A}\right) \beta\left(y_{A}\right)+g\left(y_{-}\right) \beta\left(y_{-}\right)+\int_{y_{-}}^{y_{A}}\left[\beta^{\prime}(y)-\rho f(y)\right] g(y) d y \\
& +g\left(\hat{y}_{A}\right) \gamma\left(\hat{y}_{A}\right)-g\left(y_{A}\right) \gamma\left(y_{A}\right)+\int_{y_{A}}^{\hat{y}_{A}}\left[-\gamma^{\prime}(y)-\rho f(y)\right] g(y) d y \\
& -g\left(y_{1}\right) \delta\left(y_{1}\right)+g\left(\hat{y}_{A}\right) \delta\left(\hat{y}_{A}\right)+\int_{\hat{y}_{A}}^{y_{1}}\left[\delta^{\prime}(y)+\lambda_{1}(y)-\rho f(y)\right] g(y) d y \\
& +g\left(\tilde{y}_{A}\right) \alpha\left(\tilde{y}_{A}\right)-g\left(y_{1}\right) \alpha\left(y_{1}\right)+\int_{y_{1}}^{\tilde{y}_{A}}\left[-\alpha^{\prime}(y)-\rho f(y)\right] g(y) d y \\
& -g\left(y_{A}^{\prime \prime}\right) \eta\left(y_{A}^{\prime \prime}\right)+g\left(\tilde{y}_{A}\right) \eta\left(\tilde{y}_{A}\right)+\int_{\tilde{y}_{A}}^{y_{A}^{\prime \prime}}\left[\eta^{\prime}(y)-\rho f(y)\right] g(y) d y \\
& +g\left(y_{+}\right) \theta\left(y_{+}\right)-g\left(y_{A}^{\prime \prime}\right) \theta\left(y_{A}^{\prime \prime}\right)+\int_{y_{A}^{\prime \prime}}^{y_{+}}\left[-\theta^{\prime}(y)+\lambda_{2}(y)-\rho f(y)\right] g(y) d y \\
\leq & 0 .
\end{aligned}
$$


Regrouping terms, we have

$$
\begin{aligned}
\Delta^{\prime}(0)= & g\left(y_{A}\right)\left(1-\beta\left(y_{A}\right)-\gamma\left(y_{A}\right)\right) \\
& +g\left(\hat{y}_{A}\right)\left(\gamma\left(\hat{y}_{A}\right)+\delta\left(\hat{y}_{A}\right)\right) \\
& -g\left(y_{1}\right)\left(\alpha\left(y_{1}\right)+\delta\left(y_{1}\right)\right) \\
& +g\left(\tilde{y}_{A}\right)\left(\alpha\left(\tilde{y}_{A}\right)+\eta\left(\tilde{y}_{A}\right)\right) \\
& -g\left(y_{A}^{\prime \prime}\right)\left(\eta\left(y_{A}^{\prime \prime}\right)+\theta\left(y_{A}^{\prime \prime}\right)\right) \\
& +g\left(y_{-}\right) \beta\left(y_{-}\right)+g\left(y_{+}\right) \theta\left(y_{+}\right) \\
& +\int_{y_{-}}^{y_{A}}\left[\beta^{\prime}(y)-\rho f(y)\right] g(y) d y \\
& +\int_{y_{A}}^{\hat{y}_{A}}\left[-\gamma^{\prime}(y)-\rho f(y)\right] g(y) d y \\
& +\int_{\hat{y}_{A}}^{y_{1}}\left[\delta^{\prime}(y)+\lambda_{1}(y)-\rho f(y)\right] g(y) d y \\
& +\int_{y_{1}}^{\tilde{y}_{A}}\left[-\alpha^{\prime}(y)-\rho f(y)\right] g(y) d y \\
& +\int_{\tilde{y}_{A}}^{y_{A}^{\prime \prime}}\left[\eta^{\prime}(y)-\rho f(y)\right] g(y) d y \\
& +\int_{y_{A}^{\prime \prime}}^{y_{+}}\left[-\theta^{\prime}(y)+\lambda_{2}(y)-\rho f(y)\right] g(y) d y \\
\leq & 0 .
\end{aligned}
$$

We can make sure that $\Delta^{\prime}(0) \leq 0$ if the Lagrangian functions and multipliers are 
chosen to satisfy the following inequalities:

$$
\begin{aligned}
& \beta\left(y_{A}\right)+\gamma\left(y_{A}\right) \geq 1, \\
& \gamma\left(\hat{y}_{A}\right)+\delta\left(\hat{y}_{A}\right) \leq 0, \\
& \alpha\left(y_{1}\right)+\delta\left(y_{1}\right) \geq 0, \\
& \alpha\left(\tilde{y}_{A}\right)+\eta\left(\tilde{y}_{A}\right) \leq 0, \\
& \eta\left(y_{A}^{\prime \prime}\right)+\theta\left(y_{A}^{\prime \prime}\right) \geq 0, \\
& \beta\left(y_{-}\right) \leq 0, \\
& \theta\left(y_{+}\right) \leq 0, \\
& \beta^{\prime}(y) \leq \rho f(y) \text { on }\left[y_{-}, y_{A}\right] \Rightarrow \beta\left(y_{A}\right)-\beta\left(y_{-}\right) \leq \rho F\left(y_{A}\right) \\
& \gamma^{\prime}(y) \geq-\rho f(y) \text { on }\left[y_{A}, \hat{y}_{A}\right] \Rightarrow \gamma\left(\hat{y}_{A}\right)-\gamma\left(y_{A}\right) \geq-\rho\left(F\left(\hat{y}_{A}\right)-F\left(y_{A}\right)\right) \\
& \delta^{\prime}(y) \leq \rho f(y)-\lambda_{1}(y) \text { on }\left[\hat{y}_{A}, y_{1}\right] \Rightarrow \delta\left(y_{1}\right)-\delta\left(\hat{y}_{A}\right) \leq \rho\left(F\left(y_{1}\right)-F\left(\hat{y}_{A}\right)\right)-\Gamma_{1}\left(y_{1}\right) \\
& \alpha^{\prime}(y) \geq-\rho f(y) \text { on }\left[y_{1}, \tilde{y}_{A}\right] \Rightarrow \alpha\left(\tilde{y}_{A}\right)-\alpha\left(y_{1}\right) \geq-\rho\left(F\left(\tilde{y}_{A}\right)-F\left(y_{1}\right)\right) \\
& \eta^{\prime}(y) \leq \rho f(y) \text { on }\left[\tilde{y}_{A}, y_{A}^{\prime \prime}\right] \Rightarrow \eta\left(y_{A}^{\prime \prime}\right)-\eta\left(\tilde{y}_{A}\right) \leq \rho\left(F\left(y_{A}^{\prime \prime}\right)-F\left(\tilde{y}_{A}\right)\right) \\
& \theta^{\prime}(y) \geq-\rho f(y)+\lambda_{2}(y) \text { on }\left[y_{A}^{\prime \prime}, y_{+}\right] \Rightarrow \theta\left(y_{+}\right)-\theta\left(y_{A}^{\prime \prime}\right) \geq-\rho\left(1-F\left(y_{A}^{\prime \prime}\right)\right)+\Gamma_{2}\left(y_{+}\right),
\end{aligned}
$$

where

$$
\begin{aligned}
\Gamma_{1}\left(y_{1}\right) & =\int_{\hat{y}_{A}}^{y_{1}} \lambda_{1}(y) d y, \\
\Gamma_{2}\left(y_{+}\right) & =\int_{y_{A}^{\prime \prime}}^{y_{+}} \lambda_{2}(y) d y .
\end{aligned}
$$

We must find non-negative functions $\alpha(y), \beta(y), \delta(y), \gamma(y), \eta(y), \theta(y), \lambda_{1}(y)$ and $\lambda_{2}(y)$ and a non-negative number $\rho$ satisfying those inequalities. Immediately, we deduce from above that $\gamma\left(\hat{y}_{A}\right)=\delta\left(\hat{y}_{A}\right)=\alpha\left(\tilde{y}_{A}\right)=\eta\left(\tilde{y}_{A}\right)=0$. 
We can then simplify and obtain the following system of 9 equations in 9 unknowns:

$$
\begin{aligned}
& \beta\left(y_{A}\right)+\gamma\left(y_{A}\right)=1, \\
& \alpha\left(y_{1}\right)+\delta\left(y_{1}\right)>0, \\
& \eta\left(y_{A}^{\prime \prime}\right)+\theta\left(y_{A}^{\prime \prime}\right)>0, \\
& \beta\left(y_{A}\right)=\rho F\left(y_{A}\right), \\
& \gamma\left(y_{A}\right)=\rho\left(F\left(\hat{y}_{A}\right)-F\left(y_{A}\right)\right), \\
& \delta\left(y_{1}\right)=\rho\left(F\left(y_{1}\right)-F\left(\hat{y}_{A}\right)\right)-\Gamma_{1}\left(y_{1}\right), \\
& \alpha\left(y_{1}\right)=\rho\left(F\left(\tilde{y}_{A}\right)-F\left(y_{1}\right)\right), \\
& \eta\left(y_{A}^{\prime \prime}\right)=\rho\left(F\left(y_{A}^{\prime \prime}\right)-F\left(\tilde{y}_{A}\right)\right), \\
& \theta\left(y_{A}^{\prime \prime}\right)=\rho\left(1-F\left(y_{A}^{\prime \prime}\right)\right)-\Gamma_{2}\left(y_{+}\right),
\end{aligned}
$$

where all inequalities have been replaced by an equal sign, except for (26) and (27) where we use the strict inequality. ${ }^{29}$

Using (28) and (29) in (25), we obtain that

$$
\begin{aligned}
\rho F\left(y_{A}\right)+\rho\left(F\left(\hat{y}_{A}\right)-F\left(y_{A}\right)\right) & =1, \\
& \Rightarrow \rho F\left(\hat{y}_{A}\right)=1 \\
& \Rightarrow \rho=1 / F\left(\hat{y}_{A}\right) \geq 2 .
\end{aligned}
$$

Then (28) gives

$$
\left.\left.\beta\left(y_{A}\right)=\frac{F\left(y_{A}\right)}{F\left(\hat{y}_{A}\right)} \in\right] 0,1\right]
$$

while (29) gives

$$
\gamma\left(y_{A}\right)=\frac{F\left(\hat{y}_{A}\right)-F\left(y_{A}\right)}{F\left(\hat{y}_{A}\right)} \in[0,1[.
$$

Once $\rho$ has been identified, we can use equations (31) and (32) to pinpoint the values of $\alpha\left(y_{1}\right)$ and $\eta\left(y_{A}^{\prime \prime}\right)$,which are both positive since $\rho>0$.

From (30), we have

$$
\delta\left(y_{1}\right)=\frac{F\left(y_{1}\right)-F\left(\hat{y}_{A}\right)}{F\left(\hat{y}_{A}\right)}-\Gamma_{1}\left(y_{1}\right)
$$

\footnotetext{
${ }^{29}$ The inequality needs to be strict for (26) and (27). Otherwise, we would have (using (31) or (32)) that $\rho=0$ and a contradiction with what follows.
} 
so that we can choose

$$
\Gamma_{1}\left(y_{1}\right)=\frac{F\left(y_{1}\right)}{F\left(\hat{y}_{A}\right)}-1 \geq 0 \text { and } \delta\left(y_{1}\right)=0
$$

and from (26) we obtain

$$
\alpha\left(y_{1}\right)+\delta\left(y_{1}\right)=\frac{F\left(\tilde{y}_{A}\right)-F\left(y_{1}\right)}{F\left(\hat{y}_{A}\right)}>0
$$

Likewise, from (33), we have

$$
\theta\left(y_{A}^{\prime \prime}\right)=\frac{1-F\left(y_{A}^{\prime \prime}\right)}{F\left(\hat{y}_{A}\right)}-\Gamma_{2}\left(y_{+}\right)
$$

so that we can choose

$$
\Gamma_{2}\left(y_{+}\right)=\frac{1-F\left(y_{A}^{\prime \prime}\right)}{F\left(\hat{y}_{A}\right)} \geq 0 \text { and } \theta\left(y_{A}^{\prime \prime}\right)=0
$$

and from (27) we obtain

$$
\eta\left(y_{A}^{\prime \prime}\right)+\theta\left(y_{A}^{\prime \prime}\right)=\frac{F\left(y_{A}^{\prime \prime}\right)-F\left(\tilde{y}_{A}\right)}{F\left(\hat{y}_{A}\right)}>0 .
$$

From the sign of derivatives of the functions $\alpha(y), \beta(y), \delta(y), \gamma(y), \eta(y), \theta(y), \lambda_{1}(y)$ and $\lambda_{2}(y)$, we can then immediately verify that they are non-negative in their intervals when end points are defined as above, meaning that we have indeed constructed nonnegative Lagrangian functions, and proved our claim.

\section{Proof of Proposition 8}

We first prove the properties of the function $\Phi$ before turning to those of $\Phi_{A}$. The characteristics of $\Phi_{B}$ are obtained in a similar way. Proposition 8 follows from the definitions and properties of these three curves.

\section{Step 1: The function $\Phi\left(y_{B}\right)$}

The function $\Phi$ is defined in the following way: it gives the (unique) value of $y_{A}$ such that the median income individual is indifferent between the unconstrained optimal tax schedule of party $A$ and the unconstrained optimal tax schedule of party $B$. We 
first prove that, in the space $\left(y_{B}, y_{A}\right)$, this curve goes through the point $\left(y_{m}, y_{m}\right)$, is decreasing and crosses the horizontal axis at $\left(\alpha, y_{-}\right)$with $y_{m}<\alpha<y_{+}$.

The after-tax income of the median voter under $A$ 's optimal tax is

$$
y_{A}+\int_{y_{A}}^{y_{+}}\left(y-y_{A}\right) d F
$$

whereas it is

$$
y_{m}+\int_{y_{B}}^{y_{+}}\left(y-y_{B}\right) d F
$$

under $B$ 's optimal tax, where we have used (6) and (7). The condition $y_{A}=\Phi\left(y_{B}\right)$ can thus be written

$$
y_{A}+\int_{y_{A}}^{y_{+}}\left(y-y_{A}\right) d F=y_{m}+\int_{y_{B}}^{y_{+}}\left(y-y_{B}\right) d F .
$$

a) When $y_{A}=y_{m}$ and $y_{B}=y_{m}$, it is satisfied with equality. Therefore the curve $\Phi$ goes through the point $\left(y_{m}, y_{m}\right)$.

b) We then determine how the LHS of (34) varies with $y_{A}$ :

$$
\frac{\partial}{\partial y_{A}}\left(y_{A}+\int_{y_{A}}^{y_{+}}\left(y-y_{A}\right) d F\right)=F\left(y_{A}\right) \geq 0 .
$$

The derivative of the RHS of (34) with respect to $y_{B}$ is:

$$
\frac{\partial}{\partial y_{B}}\left(y_{m}+\int_{y_{B}}^{y_{+}}\left(y-y_{B}\right) d F\right)=F\left(y_{B}\right)-1 \leq 0 .
$$

These two properties imply that the function $\Phi\left(y_{B}\right)$ is continuous and decreasing.

c) We now argue that

$$
y_{A}+\int_{y_{A}}^{y_{+}}\left(y-y_{A}\right) d F>y_{m}+\int_{y_{B}}^{y_{+}}\left(y-y_{B}\right) d F
$$

for all $y_{A} \leq y_{m}$ when $y_{B}$ is close to $y_{+}$. This comes from the observation that

$y_{A}+\int_{y_{A}}^{y_{+}}\left(y-y_{A}\right) d F=\int_{y_{-}}^{y_{A}} y_{A} d F+\int_{y_{A}}^{y_{+}} y d F \geq \bar{y}>y_{m}=\lim _{y_{B} \rightarrow y_{+}} y_{m}+\int_{y_{B}}^{y_{+}}\left(y-y_{B}\right) d F$.

This inequality, together with the continuity of $\Phi$, implies that the curve $\Phi$ crosses the horizontal axis at the point $\left(\alpha, y_{-}\right)$where $y_{m}<\alpha<y_{+}$.

The paragraph after the statement of the proposition in section 8 explains why we have type $I_{A}$ or $I I_{A}$ equilibria when $y_{m} \geq y_{A}>\Phi\left(y_{B}\right)$, and type $I_{B}$ or $I I_{B}$ equilibria when $y_{-}<y_{A}<\Phi\left(y_{B}\right)$. 


\section{Step 2: The function $\Phi_{A}\left(y_{B}\right)$}

We now construct the curve $\Phi_{A}$ and show that it is decreasing and goes through the points $\left(y_{m}, y_{m}\right)$ and $\left(y_{+}, \beta\right)$, where $y_{-}<\beta<y_{m}$. Along this curve (i.e., when $y_{A}=$ $\left.\Phi_{A}\left(y_{B}\right)\right)$, party $B$ is indifferent between playing the strategy $c_{B}^{I A}$ or $c_{B}^{I I A}$ when party $A$ proposes its optimal tax schedule. As the utility level attained by party $B$ is continuous in $y_{B}$ under both policies $c_{B}^{I A}$ and $c_{B}^{I I A}$, the function $\Phi_{A}$ is also continuous in $y_{B}$.

Take any point on $\Phi$ except $\left(y_{m}, y_{m}\right)$ and consider an increase in $y_{B}: y_{B} \rightarrow y_{B}+\delta$. We argue that for $\delta$ arbitrarily small, $B$ prefers to play $c_{B}^{I A}$ to $c_{B}^{I I A}$ when $A$ proposes its ideal policy. The argument is that when $\delta$ gets small, $c_{B}^{I A}$ gets arbitrarily close to $B$ 's ideal policy $c_{B}^{\text {opt }}$ (recall that along $\Phi$ the median voter is indifferent between the ideal policies of the two parties) while $c_{B}^{I I A}$ does not. Then it is easy to see that, for small $\delta$ enough, $B$ strictly prefers $c_{B}^{I A}$ to $c_{B}^{I I A}$.

Next consider the point $\left(y_{m}, y_{m}\right)$. We argue that at any point to the right of $\left(y_{m}, y_{m}\right)$, $B$ prefers $c_{B}^{I I A}$ to $c_{B}^{I A}$. This follows from the fact that $c_{A}^{I A}$ is the ideal policy of the median voter, $c_{m}^{o p t}$, when $y_{A}=y_{m}$. Consequently, $c_{B}^{I A}$ must also be equal to $c_{m}^{o p t}$ for $B$ to be reelected by the median voter. It then immediate follows that $c_{B}^{I I A}$ is preferred by $B$ to $c_{B}^{I A}$, as it gives less income to $y_{m}$ individuals and more to $y_{B}$ individuals.

These two facts imply that $\Phi_{A}$ is to the right of $\Phi$ and crosses the axis $y_{A}=y_{m}$ at $\left(y_{m}, y_{m}\right)$ only. Therefore $\Phi_{A}$ is decreasing over some subset of its support.

We now argue that $\Phi_{A}$ cannot increase, by showing that at any point to the right of $\Phi_{A}, B$ prefers $c_{B}^{I I A}$ to $c_{B}^{I A}$.

Consider a point $\left(y_{B}, y_{A}\right)$ on $\Phi_{A}$ (corresponding tax schedules are represented on figure 5) and increase slightly $y_{B}: y_{B} \rightarrow y_{B}+\delta$. The initial point being on $\Phi_{A}$, we have $c_{B}^{I A}\left(y_{B}, y_{B}, y_{A}\right)=c_{B}^{I I A}\left(y_{B}, y_{B}, y_{A}\right)$, namely $B$ obtains the same after-tax income by playing $c_{B}^{I A}$ or $c_{B}^{I I A}$. We then construct $c_{B}^{I A}\left(y, y_{B}+\delta, y_{A}\right)$. It is represented on Figure 5. It is identical to $c_{B}^{I A}\left(y, y_{B}, y_{A}\right)$ for values of $y \leq y_{B}^{\prime}$; for $y>y_{B}^{\prime}$, it corresponds to the dashed green curve. Then consider the strategy for $y_{B}+\delta$ that corresponds to the dashed green curve for $y$ larger than $y_{B}^{\prime}$ and to $c_{B}^{I I A}\left(y, y_{B}, y_{A}\right)$ for lower values of $y$. This tax function satisfies by construction the GBC and yields $50 \%$ of the votes to $B$. 
Moreover, it provides exactly the same net income as $c_{B}^{I A}\left(y, y_{B}+\delta, y_{A}\right)$ to people with gross income $y_{B}+\delta$. Therefore there exists a tax schedule in the family $c_{B}^{I I A}$ that is at least as good as $c_{B}^{I A}$ for individuals with income $y_{B}+\delta$. This means that $c_{B}^{I I A}$ is weakly preferred to $c_{B}^{I A}$ and thus that the equilibrium cannot be $I A$ to the right of $\Phi_{A}$ (either the curve $\Phi_{A}$ is flat or the equilibrium is $\left.I I A\right)$.

Finally we prove that $\Phi_{A}$ cannot cross the horizontal axis $y_{A}=y_{-}$, that is $\Phi_{A}\left(y_{+}\right)>$ $y_{-}$for any $y_{B} \leq y_{+}$. To do so, it is sufficient to show that $B$ strictly prefers $c_{B}^{I A}$ to $c_{B}^{I I A}$ when $y_{A} \rightarrow y_{-}$. When $y_{A}=y_{-}, A$ 's optimal tax policy consists in giving the same net income, $\bar{y}$, to everyone (the function $c_{A}^{I A}$ is flat). This has a direct implication for strategy $c_{B}^{I I A}$ : when $y_{A}$ gets arbitrarily close to $y_{-}, B$ has no other choice than proposing a tax schedule $c_{B}^{I I A}$ arbitrarily close to $c_{A}^{I A}$. It is then easy to see from Figure 3 why party $B$ prefers the schedule $c_{B}^{I A}$ : this schedule gives less than $\bar{y}$ to individual with income $y<y_{m}$ in order to increase after-tax consumption of individuals $y_{B}^{\prime}<y \leq y_{+}$. We then have that $c_{B}^{I A}\left(y_{B}, y_{B}, y_{-}\right)>c_{B}^{I I A}\left(y_{B}, y_{B}, y_{-}\right)$.

\section{Step 3: The function $\Phi_{B}\left(y_{B}\right)$}

The technique used for constructing $\Phi_{B}$ is similar to the one used for $\Phi_{A}$. 


\section{References}

Abreu, D. (1988). On the theory of infinitely repeated games with discounting. Econometrica 52(2), 383-96.

Banks, J. S. and J. Duggan (2008). A dynamic model of democratic elections in multidimensional policy spaces. Quarterly Journal of Political Science 3(3), 26999.

Baron, D. and E. Kalai (1993). The simplest equilibria of a majority division game. Journal of Economic Theory 61(2), 290-301.

Bohn, H. and C. Stuart (2005). Voting and nonlinear taxes in a stylized representative democracy. Working paper, UCSB.

Carbonell-Nicolau, O. and E. A. Ok (2007). Voting over income taxation. Journal of Economic Theory 134(1), 249-86.

De Donder, P. and J. Hindriks (2003). The politics of progressive income taxation with incentive effects. Journal of Public Economics 87, 2491-505.

Duggan, J. (2000). Repeated elections with asymmetric information. Economics and Politics 12, 109-36.

Duggan, J. and M. Fey (2005). Electoral competition with policy-motivated candidates. Games and Economic Behavior 51, 490-522.

Persson, T. and G. Tabellini (2000). Political Economics: Explaining Economic Policy. MIT Press.

Plott, C. R. (1967). A notion of equilibrium and its possibility under majority rule. American Economic Review 57, 787-806.

Roberts, K. (1977). Voting over income tax schedules. Journal of Public Economics 8, $329-40$.

Roëll, A. (1996). Voting over nonlinear income tax schedules. unpublished.

Roemer, J. E. (2001). Political competition: Theory and applications. Cambridge: Harvard University Press. 
Roemer, J. E. (2006). Democracy, education and equality. Cambridge University Press.

Roemer, J. E. (2009). A theory of income taxation where politicians focus upon core and swing voters. Social Choice and Welfare forthcoming.

Romer, T. (1975). Individual welfare, majority voting and the properties of a linear income tax. Journal of Public Economics 7, 163-68. 


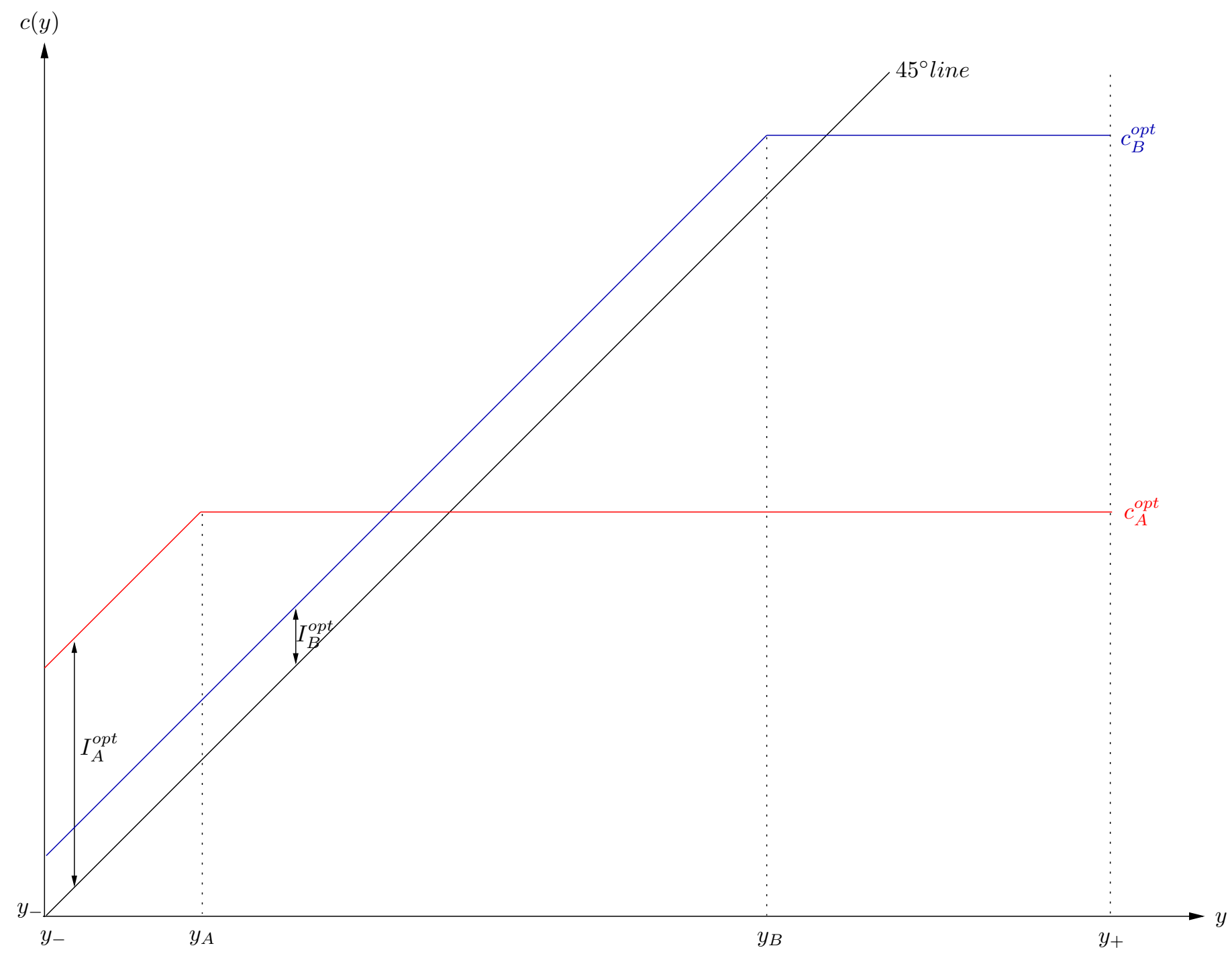

Figure 1: Optimal tax schedules of the two parties 


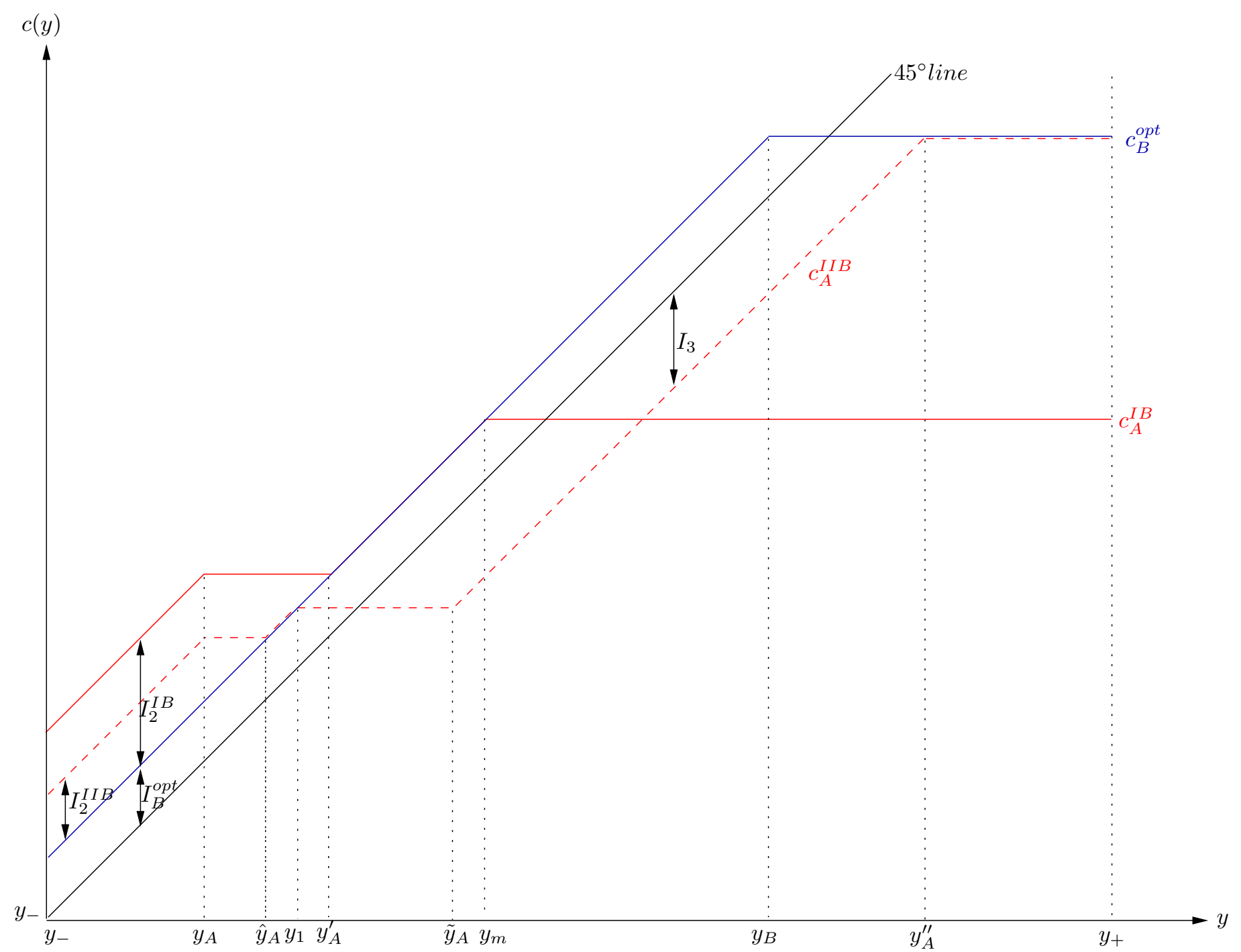

Figure 2: Party $B$ proposes its unconstrained optimal policy 


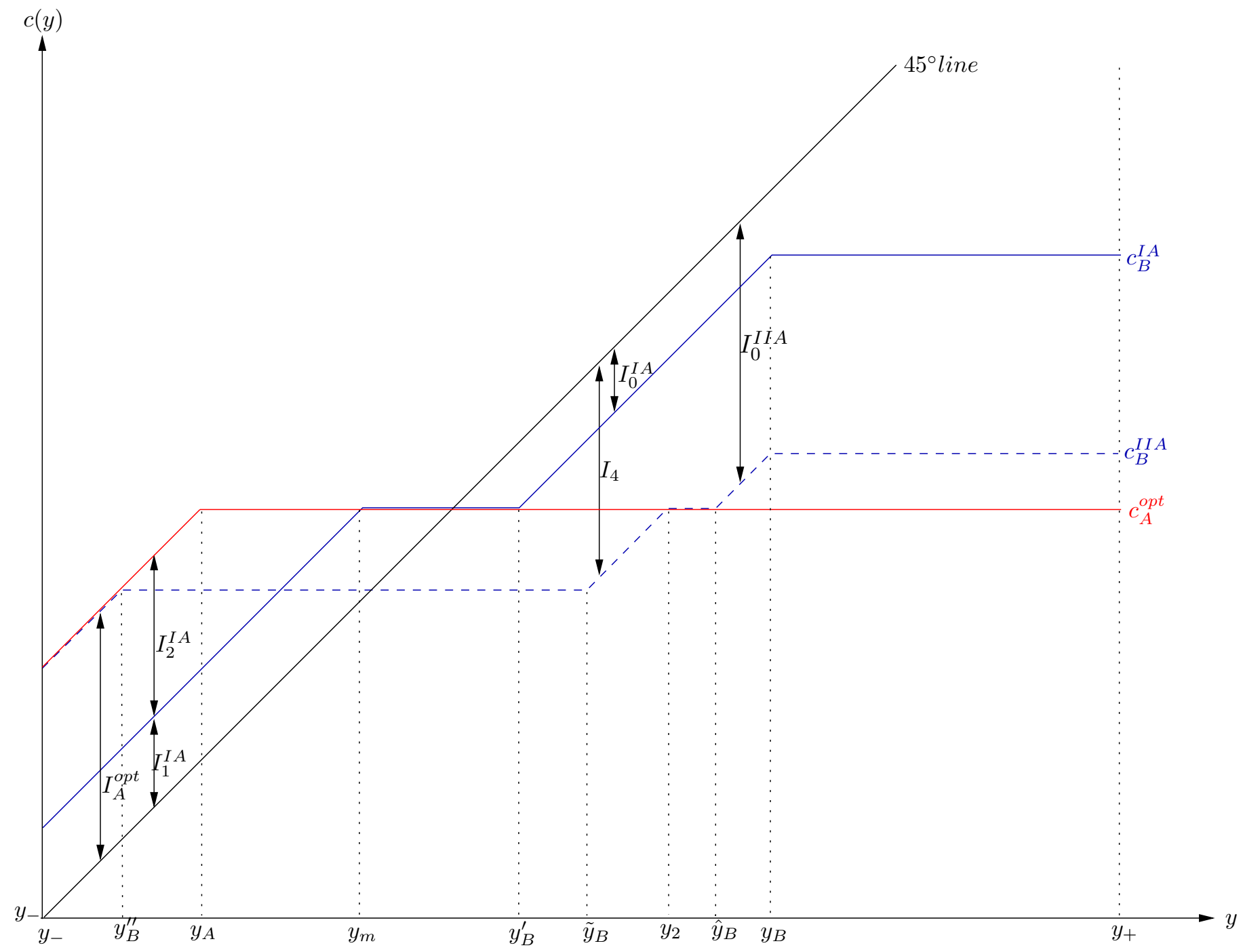

Figure 3: Party $A$ proposes its unconstrained optimal policy 


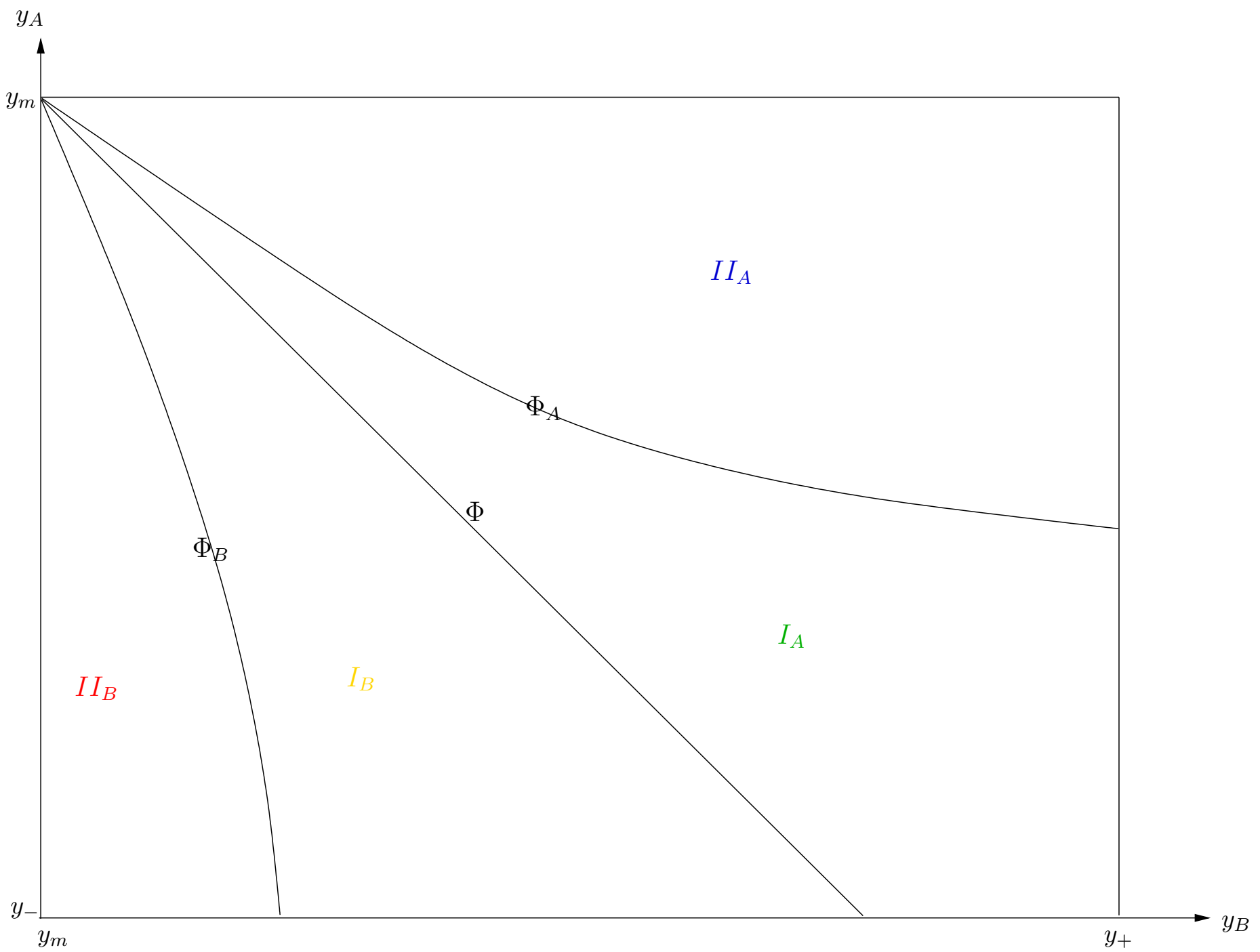

Figure 4: Partition of equilibria 


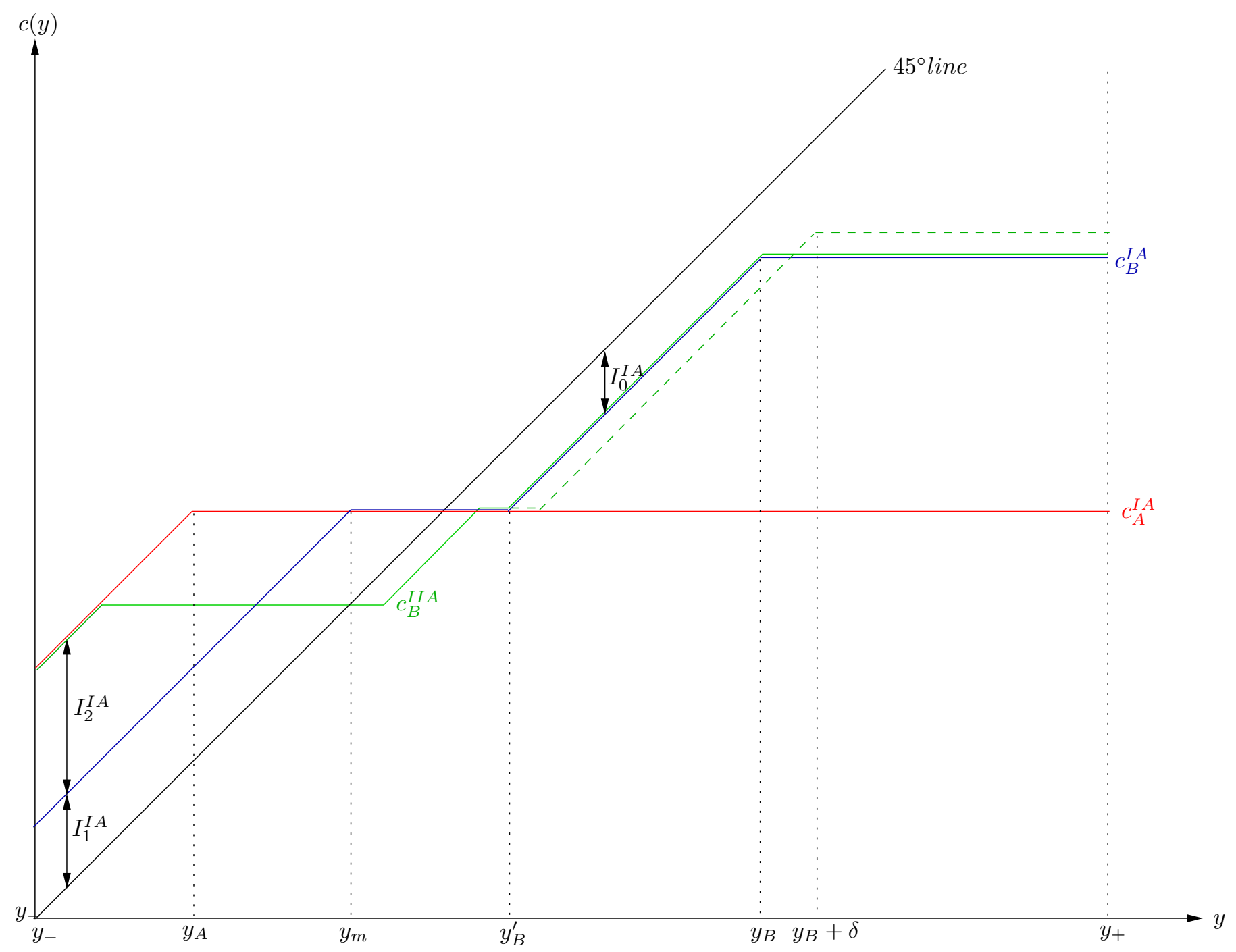

Figure 5: Construction of $\Phi_{A}$ 